\title{
(IN)SINCERIDAD REGULATORIA: (DES)CONSIDERANDO LOS COSTOS DE HACER CUMPLIR LA REGULACIÓN AMBIENTAL
}

\author{
José A. Hernández R. \\ Universidad San Sebastián \\ Juan C. Monckeberg F.
}

\begin{abstract}
RESUMEN: Este artículo identifica un problema en la práctica regulatoria ambiental de Chile: la adopción de regulación sustantiva con costos de fiscalización y sanción que son ignorados o muy subestimados. Aunque esta práctica viola la regulación adjetiva, puede explicarse por un diseño institucional que separa funciones en diferentes organismos: el Ministerio de Medio Ambiente tiene incentivos para adoptar regulación sustantiva e inmediatamente internalizar el crédito político, externalizando el eventual costo del fracaso en la Superintendencia de Medio Ambiente. La experiencia comparada maneja este problema a través de un organismo independiente de control de calidad de las evaluaciones de impacto regulatorio.

PALABRAS ClAVE: regulación ambiental, fiscalización, cumplimiento, costos de cumplimiento.

RECIBIDO: marzo 2018; ACEPTADO: julio 2018.
\end{abstract}

José A. Hernández R. Abogado de la Universidad de Chile y magíster (c) en derecho por la misma universidad. Ex asesor legal de la SMA. Hoy es asesor legal del Tercer Tribunal Ambiental y profesor de derecho ambiental en la Universidad San Sebastián. Email: jhernandezr@docente.uss.cl.

Juan C. Monckeberg F. Geógrafo de la Pontificia Universidad Católica de Chile y magíster en derecho ambiental por la Universidad de Chile. Superintendente del medio ambiente entre 2012 y 2014. Email: jcmoncke@uc.cl.

Los autores agradecen a los árbitros anónimos de Estudios Públicos, cuyos comentarios fueron muy útiles para presentar de mejor manera esta investigación. 


\title{
REGULATORY (IN)SINCERITY: (DIS)REGARDING THE COSTS TO ENFORCE ENVIRONMENTAL REGULATION
}

\begin{abstract}
This paper identifies a problem within the environmental regulatory practice in Chile: the adoption of substantive regulation which enforcement costs are ignored or very underestimated. Though this practice clearly violates the adjective regulation, it can be explained through an institutional design that separate functions among different agencies: the Ministerio de Medio Ambiente has incentives to adopt substantive regulation and immediately internalize political credit, externalizing the cost of its eventual failure in the Superintendencia de Medio Ambiente. Comparative experience address this problem by setting an independent organization to perform quality control over regulatory impact assessment.
\end{abstract}

KEYwORDs: environmental regulations, enforcement, compliance, compliance costs.

RECEIVED: March 2018; ACCEPTED: July 2018.

\section{INTRODUCCIÓN}

a búsqueda de un adecuado diseño institucional es un tema recurrente de política pública, ya que los funcionarios que dirigen organizaciones a menudo imputan los fracasos de gestión a errores de diseño, reales o no, para evitar su responsabilidad (Hood 2011, 30).

Desde una perspectiva sociológica, las instituciones son patrones de conductas estables, valoradas y recurrentes (Huntington 1965, 394), resultantes de entendimientos mutuos de preferencias y conductas de optimización de individuos y organizaciones (Crawford y Ostrom 1995, 582). Estos patrones son explicados mediante dos aproximaciones: una centrada en reglas y normas de conducta, formales e informales, y por las características de su cumplimiento, que estructuran la interacción humana repetida, a través de restricciones e incentivos (North 1989, 1321), y otra centrada en equilibrios resultantes espontáneamente de la conveniencia de los involucrados (Hodgson 2006, 12).

Por su parte, las organizaciones están conformadas por individuos unidos por algún propósito común para lograr ciertos fines (North 1994, 361), necesitando de coordinación racional para alcanzarlos, por lo que se crean divisiones de trabajo y función, y se atribuyen cargos, jerarquía 
y responsabilidades (Chell 1987, 157). Por tanto, reconocer las reglas y normas formales e informales de las organizaciones es un elemento necesario para describir y predecir el funcionamiento de las instituciones. Por ello, el diseño de las organizaciones requiere del establecimiento de reglas formales para conformar una institucionalidad, como a su vez necesita que a los organismos que lo integran se les asigne posición y funciones, además de mecanismos de comunicación y vigilancia. Este tema ya lo hemos analizado en otra ocasión (Monckeberg et al. 2017, 11-12).

Si bien las reglas formales configuradas como deberes o prohibiciones establecen condicionantes de conducta, los directivos de estas organizaciones tienen incentivos y desincentivos personales de diversa índole. Por esto, dados la asignación de funciones, los incentivos personales y el horizonte temporal, es perfectamente posible que uno de los organismos que conforman el diseño organizativo de una institucionalidad subutilice el mecanismo de comunicación, pues su directivo carece de incentivos. En el corto plazo, el directivo y su organización internalizan la ganancia política de su decisión, pero en el mediano plazo se externaliza el costo político en otro directivo y organismo.

Esta estrategia de internalización de ganancias y externalización de costos por directivos - e incluso por funcionarios - es inherente al funcionamiento de todo diseño institucional. No obstante, éste puede incluir reglas formales, como mecanismos de planificación y control, que hagan más costosa esta externalización. En ese sentido, consideramos que este problema está presente en el actual diseño de la institucionalidad ambiental. Así, a través de evidencia, este trabajo muestra la realidad de la implementación de la reforma a la institucionalidad ambiental, y la imposibilidad física y, en ciertos casos, también jurídica de desempeñar a plenitud el mandato legal de vigilar y hacer cumplir las regulaciones ambientales.

Como veremos, el actual diseño de la institucionalidad ambiental sitúa la generación de regulaciones y su vigilancia en organismos distintos, uno con predominio político sobre otro, lo que ha sido identificado como un problema generalizado del diseño institucional chileno (OECD 2016a, 77-78). La diferenciación de funciones, en general, permite determinar mejor la estrategia para reclamar crédito político y evitar costo político, lo que produce el juego de la culpa, cuya lógica es evitar la carga de la culpa situándola en otra parte, el que triunfa ante 
el discurso de buena gobernanza, y que es imperativo para funcionarios designados y electos, quienes manejan inherentemente los conceptos de culpa y riesgo de culpa (Hood 2011, 4-5 y 24).

Si bien ha sido muy estudiada en el ámbito jurídico, Hood define la culpa como el acto de atribuir algo percibido como malo o incorrecto a alguien en un momento dado, y que contiene dos elementos: la percepción de daño evitable - daño que pudo evitarse si se hubiese manejado de otra forma - y la de agente responsable — daño causado por acciones $u$ omisiones atribuibles a alguien-. Estas combinaciones, al ser percepciones en el tiempo, tienden a variar; por tanto, sostiene que hay tres variables para evadir la culpa, que son tiempo, percepción del daño y percepción de agente responsable, $\mathrm{y}$ hay estrategias preventivas y reactivas para dicho fin (Hood 2011, 6).

Hood también define el crédito como el acto de atribuir algo percibido como bueno o positivo a alguien, esto es, lo opuesto a la culpa; y tiene tres variables similares, no para evadirla sino reclamarla, que son tiempo, percepción del beneficio y percepción de agente responsable, y también hay estrategias preventivas y reactivas (Hood 2011, 9).

Lo anterior se percibe cotidianamente, pues políticos elegidos y funcionarios designados buscan reclamar crédito y evitar culpa porque esto mejorará sus posibilidades de ser nuevamente elegidos, designados, promovidos o incluso mantener su reputación durante y después de sus vidas, como legado. Para evitar la culpa o reclamar el crédito se pueden usar estrategias de presentación, de agencia y de política (Hood 2011, 17-22). Para efectos de este trabajo, es particularmente interesante la primera.

La estrategia de presentación maneja percepción de daño y tiempo. Esto se hace a través de excusas que limitan la culpa, o justificaciones que la transforman en crédito. También se utilizan otros medios para conducir la percepción pública, como el manejo comunicacional, decidiendo qué información se hace pública, cuándo y cómo, o simplemente desviando la atención, como con la conocida cortina de humo (Hood 2011, 47-66).

En el caso de diseño organizativo chileno del sector ambiental, si bien el Ministerio del Medio Ambiente (MMA) diseña la regulación, no interactúa permanentemente con los regulados. Esta interacción corresponde hacerla puntualmente al Servicio de Evaluación Ambiental 
(SEA) — en la evaluación de proyectos - y de manera permanente a la Superintendencia del Medio Ambiente (SMA) —en la fiscalización-. El crédito político que busca reclamar el MMA, y que por cierto es la función para el cual está diseñado, es la generación de nueva regulación, pero está normalmente desligado de la responsabilidad de administrarla y fiscalizarla.

Como el éxito de la gestión ministerial se mide por su capacidad de aprobar regulación, toda dificultad o alto costo de fiscalización y cumplimiento con cargo fiscal que se haga ver obstaculizaría su aprobación, así como el necesario apoyo de más actores involucrados, dado al carácter transversal de la normativa ambiental. No obstante, este problema es transversal a la regulación, especialmente cuando se requiere efectuar una evaluación de impacto regulatorio (EIR) previo a su adopción. Es entonces cuando deben evidenciarse estos costos (Marneffe y Vereeck 2011, 346).

El problema ha sido identificado en la experiencia comparada, por lo que, para prevenir la disfunción del sistema regulatorio causada por la desconsideración de estos costos, algunos países han establecido organismos independientes encargados de su correcta determinación. Para indagar sobre la materia, este trabajo se ordena de la siguiente forma:

La primera parte expone algunos mecanismos, recomendaciones y experiencias comparadas en el marco de la política denominada mejor regulación, para disminuir el riesgo de este problema, además de cómo la OECD lo ha identificado en Chile en el marco de la nueva institucionalidad ambiental.

La segunda parte expone sobre el diseño institucional del sector ambiental, identificando las funciones generales asignadas a cada organismo, junto a la inequidad presupuestaria y la baja capacidad de procesamiento, lo que es catalizador de la "in"sinceridad regulatoria.

La tercera parte muestra cómo el MMA, con evidencia obtenida de los expedientes públicos de adopción de regulación sustantiva ambiental, ignora la obligación legal y reglamentaria de hacer una correcta determinación de los costos requeridos para vigilar la regulación ambiental y hacerla cumplir; es decir, se identifica el mismo problema que la experiencia comparada detectó y que intenta resolver con la creación de organismos independientes de control de calidad de las evaluaciones de impacto regulatorio. 
La cuarta parte presenta conclusiones y recomendaciones para manejar el problema regulatorio identificado, a partir de la experiencia comparada.

\section{EXPERIENCIA COMPARADA SOBRE SINCERIDAD REGULATORIA}

\subsection{OECD: transparentar costos de fiscalización} para una mejor regulación

Si bien se cree que vivimos en una época de desregulación, la OECD sostiene que tal situación es una confusión discursiva en los procesos de liberalización de mercados y de privatización, pues éstos realmente han aumentado las regulaciones y, por tanto, han obligado a la creación de nuevas instituciones y regímenes regulatorios (OECD 2002, 22).

Un asunto crucial en el logro de los objetivos regulatorios es la detección de infracciones y la estrategia de manejo de los infractores. Desde una perspectiva general, el objetivo regulatorio es siempre obtener conductas de cumplimiento, manteniendo a los regulados cumplidores en esa conducta y moviendo la de los incumplidores hacia el cumplimiento. Como se ha señalado, desde la perspectiva del infractor racional, su toma de decisiones considerará la probabilidad de detección de la infracción, la severidad de la sanción aplicable y el beneficio esperado a partir de la infracción. Desde la perspectiva de la Administración, entonces, es preciso revisar los niveles de detección y condena, y los niveles de severidad de la sanción para obtener niveles óptimos de cumplimiento (Becker 1968, 204). Incrementar los niveles de detección y condena, manteniendo los niveles de severidad de las sanciones, puede disminuir los incentivos para infringir, pero esto conlleva necesariamente un aumento del gasto público; por lo que, aumentar sólo los niveles de severidad de la sanción puede producir el mismo efecto a un menor costo.

Sin embargo, todo lo anterior asume que no se incrementa el número de potenciales infractores, ya sea con nuevas tipificaciones o expandiendo la aplicación de las tipificaciones vigentes. Un aumento de los potenciales infractores conlleva necesariamente una disminución de la capacidad de detección y condena. Esto puede frustrar el objetivo de la 
nueva regulación. Tal como ha señalado la $\mathrm{OECD}$, antes de adoptar nueva regulación, o revisar la existente, es necesario evaluar la capacidad administrativa para aplicarla y hacerla cumplir, pues el estado generalizado de incumplimiento puede deberse a la baja probabilidad de detección y condena si los recursos para dicha labor son inadecuados. Por tanto, esto debe incluirse al calcular los costos de cumplimiento (OECD 2002, 80).

Recientemente, la misma OECD reafirmó que los costos de cumplimiento son aquéllos en que incurren las empresas a las que se dirige la regulación con el fin de adoptar las acciones necesarias para cumplirlas, así como los costos estatales en la administración de la regulación y la comprobación del cumplimiento. Estos últimos están directamente relacionados con el logro de los objetivos regulatorios subyacentes, e incluyen el desarrollo e implementación de sistemas de permisos o registros, de evaluación de solicitudes y procesamiento de renovaciones, de diseño e implementación de sistemas de inspección, auditoría y sanciones por incumplimiento (OECD 2014, 12-13).

Si bien dicho organismo considera que la determinación de estos costos no es problemática, pues son costos internos de la Administración y usualmente será necesario preparar solicitudes al Ministerio de Hacienda para incrementar el presupuesto y cubrir los costos de establecer o expandir funciones, advierte que su adecuada estimación es necesaria para el desarrollo de una estrategia de implementación y cumplimiento, y se requiere prestarle mucha atención para retroalimentar con mejoras al diseño regulatorio (OECD 2014, 38-39).

Por su parte, este organismo recomienda también el establecimiento de mecanismos e instituciones que provean activamente supervisión sobre procedimientos y metas de política regulatoria, a través de un organismo permanente encargado de la supervisión regulatoria - establecido cerca del centro de gobierno e independiente de influencia política—, al que debe asignársele funciones y tareas para permitir la toma de decisiones regulatorias basada en evidencia de alta calidad (OECD 2012, 9). Además, sugiere incluir la evaluación de impacto regulatorio (EIR) en las etapas tempranas de formulación de propuestas regulatorias, y que cuando estas últimas tengan un impacto significativo, la evaluación ex ante de costos, beneficios y riesgos debe ser cuantitativa, siempre que sea posible, recordando que deben incluirse 
costos directos e indirectos de empresas, personas y administración (OECD 2012, 10-11).

El caso ambiental es paradigmático, y en él se identifica lo que Hood indica respecto de estrategias de reclamación de crédito político. En ese sentido, la OECD observa que, en la regulación ambiental, la EIR se desarrolla en un entorno naturalmente hostil, pues a menudo está en conflicto con el cronograma político - que pueden depender del uso de ventanas de oportunidad-, y además puede limitar el espacio de maniobra para que los actores políticos alcancen sus metas - ya que la EIR analiza los aspectos positivos y negativos de las propuestas-, lo que redunda en que a menudo se desarrolle de forma superficial y no transparente, sólo para legitimar un curso predeterminado de acción, en lugar de proveer evidencia balanceada, a favor y en contra de la regulación propuesta (OECD 2011, 8-9). En ese sentido, este organismo advierte que, si la EIR considera los costos de tramitación de permisos y de vigilancia, pueden aumentar los costos totales de la regulación entre 20 y 38 por ciento (OECD 1999, 252).

Para efectos de este estudio, analizaremos enseguida y de forma resumida la experiencia en esta materia acotada a la creación de organismos independientes para el control de calidad de la EIR en los Países Bajos y Alemania, y la evaluación de los costos estatales de administración y vigilancia de la regulación. Respecto de las demás experiencias europeas con estos organismos independientes, como la noruega con el denominado Regelrådet o la británica con el Regulatory Policy Committee, por razones de espacio no se incluyen en este artículo.

También se deja de lado la experiencia norteamericana en el nivel federal, pues, a pesar de ser paradigmática, el organismo encargado de esta evaluación, denominado Office of Information and Regulatory Affairs (OIRA), depende directamente del poder ejecutivo. Aun cuando la Executive Order 12866 (1993) ordena evaluar por anticipado los costos de toda regulación propuesta que clasifique cuantitativamente como significativa -incluyendo los costos directos e indirectos en que incurre la Administración en gestionarla, vigilarla y hacerla cumplir-, la dependencia política de la OIRA es funcional al control de la agenda regulatoria, que puede ser disputada entre el poder ejecutivo y las agencias federales, como expresión de los fenómenos de politización y centralización (Acs y Cameron 2013, 444-445). 


\subsection{Países Bajos: la experiencia Actal / ATR / T11}

Cuando en 1984 la Comisión Geelhoed presentó un informe final sobre intervención estatal concluyó que la estructura institucional neerlandesa tenía una enorme responsabilidad en la dictación de regulaciones excesivamente complejas, pesadas y extensivas; que usualmente el gabinete hacía compromisos y tomaba decisiones regulatorias sin valorar su factibilidad, coherencia y viabilidad jurídica, a pesar de sucesivas instancias de coordinación; y que esto, junto con otros aspectos, causaba que la regulación fuese ineficiente, inefectiva o incluso imposible de implementar (OECD 1999, 7).

Para adecuar la política regulatoria, en 1995 se comenzó el programa $\mathrm{MDW}^{1}$, con la finalidad de disminuir la carga regulatoria para empresas y Administración. A continuación, en 2011 se estableció el organismo asesor independiente $\mathrm{Actal}^{2}$, encargado de asesorar directamente al gobierno parlamentario sobre la materia, el que en 2017 fue transformado y renombrado $\mathrm{ATR}^{3}$. Además, desde 2002, el gabinete acordó realizar para cada regulación estudios de (i) evaluación de impacto en negocios, (ii) evaluación de impacto ambiental, (iii) análisis costo beneficio y (iv) evaluación de factibilidad y fiscalización.

Esta última evaluación obliga a determinar: (i) cuál es el grupo objetivo que se afectará con la regulación y su tamaño; (ii) cuáles efectos tendrá la regulación para el personal administrativo que existe en relación con el necesario para vigilarla y hacerla cumplir; (iii) cuál es el grado de cumplimiento espontáneo de la regulación, la escala del control y vigilancia de la regulación y posibilidades de cumplirla, y la escala de sanciones y posibilidades de cumplirla; (iv) cuáles organizaciones van a implementar, vigilar y hacer cumplir la regulación, su opinión sobre factibilidad y fiscalización, y todos los costos asociados de implementación, fiscalización, sanción y acatamiento de sanciones; y (v) cuáles serán las consecuencias en la carga de trabajo de los tribunales (OECD 2011, 15).

${ }^{1}$ Marktwerking, Deregulering en Wetgevingskwaliteit: Fuerza de Mercado, Desregulación y Calidad Legislativa.

${ }^{2}$ Adviescollege Toetsing Administratieve Lasten: Junta Asesora para Evaluación de la Carga Administrativa.

${ }^{3}$ Adviescollege Toetsing Regeldruk: Junta Asesora para Evaluación de la Presión Regulatoria. 
Incluso, el Ministerio de Justicia neerlandés desarrolló una lista de control, denominada T11, que incluye tres dimensiones sobre calidad regulatoria:

i) dimensión de cumplimiento espontáneo, para pronosticar cuánto cumplimiento habrá en ausencia de vigilancia, utilizando para esto (1) los niveles de conocimiento y comprensión de las normas, (2) los costos y beneficios de su cumplimiento, (3) los niveles de aceptación de su razonabilidad, (4) las actitudes generales de cumplimiento de los regulados y (5) la posibilidad de sanciones privadas;

ii) dimensión de control del cumplimiento, para pronosticar la probabilidad de detección de conductas infractoras, que está directamente relacionado con el nivel de cumplimiento, utilizando para esto los factores de probabilidades (6) de denuncia, (7) de inspección administrativa y (8) de detección efectiva de incumplimiento en inspección, además de (9) la habilidad del organismo encargado para elegir efectivamente los objetivos a fiscalizar, y

iii) dimensión de sanción del incumplimiento, para pronosticar el valor esperado de sanción por incumplimiento, es decir, (10) la probabilidad de que una sanción efectivamente se imponga y ejecute, y (11) la severidad y tipo de la misma (OECD 1999, 19-20).

La T11 permite desarrollar la EIR con un mayor grado de confianza y objetividad, apuntando no sólo a la etapa de diseño regulatorio, sino también a la de su implementación, vigilancia y cumplimiento.

\subsection{Alemania: la experiencia NKR}

En Alemania, bajo la política de "mejor regulación", en 2006 se estableció por ley federal el $\mathrm{NKR}^{4}$, un organismo colegiado asesor independiente, para prestarle apoyo al gobierno federal parlamentario en reducir la burocracia y mejorar la regulación. Para este fin, dicho organismo ha intentado asegurar suficientes niveles de transparencia en el cálculo de costos para la toma de decisiones legislativas y administrativas, en especial para visibilizar los costos financieros y los requerimientos de tiempo que incurrirán ciudadanos, empresas y Administración.

\footnotetext{
${ }^{4}$ Nationaler Normenkontrollrat: Consejo Nacional de Control Regulatorio.
} 
Este organismo prepara un reporte para cada iniciativa regulatoria y lo notifica al ministerio que tramita la regulación. En ese sentido, para 2010, dicho organismo declaró que estaba trabajando en una definición comprensiva de "costos de cumplimiento", pero advirtió que en estos se incluyen los costos de fiscalización y sanción en que incurre ineludiblemente la Administración (NKR 2010, 45-46).

De forma más detallada, en 2012 el citado organismo emitió directrices para la identificación y presentación de costos de cumplimiento en propuestas legislativas federales, insistiendo que, para las autoridades públicas, estos incluyen primariamente los relativos al procesamiento de solicitudes o el desarrollo de tareas fiscalizadoras. Dicho documento sostiene que un primer paso es identificar el número de casos que se espera administrar y someter a monitoreo y control de forma periódica u ocasional; y que un segundo paso es identificar los costos de cumplimiento por caso, teniendo que identificarse cuáles son las principales actividades realizadas por las unidades administrativas para cumplir con el procesamiento, y, a partir de éstos, calcular los costos de material y personal necesarios bajo el modelo estandarizado de costos (NKR 2012, 28-29).

Bajo ese marco institucional también ha sido posible desarrollar la EIR con un mayor grado de confianza y objetividad, apuntando no sólo a la etapa de diseño regulatorio, sino que también a la de su implementación, vigilancia y cumplimiento, tal como en la experiencia neerlandesa.

\subsection{Análisis del marco institucional chileno por la OECD}

En 2017, en su calidad de miembro de la OECD, nuestro país fue sometido a escrutinio en relación con la EIR. El informe final, que estudió nuestro marco legislativo, señaló que cada proyecto de ley es enviado por el ministerio patrocinante al Ministerio Secretaría General de la Presidencia con una evaluación de impacto financiero; que si el proyecto incurre en gasto financiero necesita ser aprobado por la Dirección de Presupuestos —encargada de determinar su impacto presupuestarioy que el Instructivo Presidencial n. ${ }^{\circ}$ 2/2016 es un paso correcto, porque obliga a los ministerios patrocinantes de proyectos de ley a presentar un informe de productividad del mismo (OECD 2017, 40-42).

Pero, aunque dicho informe no lo señale, observaremos que algunos informes financieros de la Dirección de Presupuestos son muy 
simples, inexplicables e incluso contradictorios. A modo de ejemplo, el informe financiero del Proyecto de Ley para la Gestión de Residuos y Responsabilidad Extendida del Productor indicó que, si bien su fiscalización y sanción quedarán entregadas a la SMA, "los recursos que pudiese demandar (...) dependerán de lo que consigne anualmente la Ley de Presupuestos para el Fondo Nacional de Gestión de Residuos" (Dipres 2013). En cambio, luego de que se incorporaran algunas indicaciones, el segundo informe financiero indicó que "el mayor gasto fiscal asociado (...) considera los recursos para financiar los gastos en personal y de operación, tanto a nivel central como en regiones, para las nuevas funciones establecidas en el proyecto", que "el mayor gasto anual estimado en régimen por este concepto es de 3.963 millones de pesos, al que se llegará al tercer año", y que "el mayor gasto fiscal (...) se financiará con cargo a los recursos que se establezcan en las respectivas leyes de presupuestos" (Dipres 2015d). Es decir, si bien el primer informe reconoce la mayor carga de trabajo del organismo fiscalizador, sin explicitarla y cuantificarla, el segundo la cuantifica sin mayor explicación, y en ambos casos entregó su financiamiento a los vaivenes de la discusión política presupuestaria anual.

De forma similar, para la reforma tributaria del año 2014, que entre otras modificaciones estableció impuestos verdes a ciertas fuentes móviles y estacionarias, y que respecto de estas últimas le asignó a la SMA la determinación del hecho gravado y su verificación, el informe financiero no indicó costo alguno adicional para este organismo. Además, afirmó que, "para los años 2015 y siguientes, los gastos que corresponda financiar por efecto de la aplicación de las normas del presente proyecto de ley serán incluidos en las correspondientes leyes de presupuesto" (Dipres 2014). Es decir, aunque asumió que la SMA tendrá una carga adicional de trabajo, sin explicitarla y cuantificarla públicamente, entregó también su financiamiento a los vaivenes de la discusión política presupuestaria anual.

Si a nivel legislativo el tema de los costos de cumplimiento es preocupante, a nivel reglamentario es peor. Como indica la OECD, si bien la Administración efectúa una revisión jurídica de los proyectos de ley y de sus reglamentos, falta la aplicación generalizada de la EIR para comprender si hay evidencia sólida de que los beneficios de la intervención regulatoria superarán a sus costos, por lo que recomienda promo- 
ver la evaluación ex ante, y deseablemente convertirla en obligatoria (OECD 2016a, 74).

El mismo informe pone como ejemplo casi solitario de EIR en nuestro país al procedimiento de elaboración de la regulación ambiental derivada de la Ley 19.300, respecto de lo cual son necesarias la preparación y publicación de los denominados AGIES -Análisis General de Impacto Económico y Social_- los que son elaborados por el Departamento de Economía Ambiental del MMA. No obstante, advierte el informe, no hay un mecanismo formal de control de calidad una vez que se entrega este documento (OECD 2016a, 98-101). Este problema es crítico, como se evidenciará más adelante en este trabajo.

Como mostraremos enseguida, creemos que existe un problema estructural relacionado con la separación de funciones entre el MMA y la SMA, reforzado por la tolerada inobservancia del MMA respecto de su propia regulación adjetiva. Si ambas funciones estuviesen concentradas en un mismo organismo, éste difícilmente adoptaría una regulación que no pudiese fiscalizar, por cuanto será el único punto de imputación de culpa, es decir, se lo percibirá como irresponsable por su mala fiscalización; aunque cabe la posibilidad de que, dadas las estrategias señaladas en la introducción (Hood 2011, 47-66), se maneje el tiempo y que, para internalizar la ganancia política, una administración adopte irresponsablemente una regulación que deberá fiscalizar la siguiente, emergiendo entonces la culpa e imputándosele a esta última. Por eso, no sugerimos que necesariamente deban concentrarse ambas funciones en un organismo, sino que un remedio eficaz es situar la revisión de la calidad de la EIR en un organismo independiente.

Cabe señalar que este diagnóstico sobre la criticidad de la EIR en la normativa ambiental nacional, así como de la ausencia de mecanismos de control de su calidad, está identificado desde el siglo pasado, discutido, sin ir más lejos, en Estudios Públicos. Se señaló entonces que "el gran problema de la institucionalidad pública chilena... radica en el escaso o nulo poder fiscalizador de sus instituciones" (Katz et al. 1995, 178), y que "debe existir constante preocupación por evaluar los costos derivados de los problemas ambientales, así como los costos de control incurridos, tanto por los privados como por el sector público" (Katz et al. 1995, 191). 
Dado que el diseño institucional del sector ambiental es esencial para entender el problema, en la siguiente parte lo estudiaremos brevemente, aunque de forma crítica, y mostraremos algunos números relacionados con la distribución presupuestaria interna del sector, lo que puede servir para calibrar sus capacidades operativas.

\section{DISEÑO INSTITUCIONAL DEL SECTOR AMBIENTAL}

Como es conocido, en el año 2010, por medio de la Ley 20.417, se reformó el diseño orgánico del sector ambiental, creando el Ministerio de Medio Ambiente (MMA), el Servicio de Evaluación Ambiental (SEA) y la Superintendencia de Medio Ambiente (SMA). Pero, para comprender mejor el diseño institucional del sector ambiental en Chile no basta con identificar los organismos que lo integran, sino que se necesita escrutar cuidadosamente sus funciones regulatorias. Este análisis muestra un panorama de altos costos de coordinación.

Para escrutar las funciones regulatorias, ocuparemos la diferenciación entre regulación ambiental adjetiva y sustantiva respecto de la Ley 19.300, que sostiene que la regulación sustantiva tiene como objetivo repercutir en la conducta de los administrados y de la Administración, mientras que la regulación adjetiva, o reglamentación procedimental, tiene como objetivo establecer los procedimientos de elaboración, aprobación, implementación y evaluación de la regulación sustantiva (Pinilla y Hernández 2016, 528-532).

De esta forma, si se examinan los artículos 32 inciso 3, 40 inciso 2 , y 44 inciso 2 de la Ley 19.300, es posible reconocer que ellos habilitan, de forma condicionada, el ejercicio de la potestad reglamentaria de ejecución para adoptar regulación adjetiva, en forma de reglamentos procedimentales específicos para la dictación de normas de calidad ambiental (NCA), normas de emisión (NE) y planes de prevención y descontaminación atmosférica (PPDA), respectivamente.

Pero si se examinan los artículos 32 inciso 1 y 2, 40 inciso 1, 44 inciso 1 , de la misma ley, es posible reconocer que ellos también habilitan el ejercicio de la potestad reglamentaria de ejecución para elaborar la regulación sustantiva. Los citados artículos ordenan establecer las NCA, NE y PPDA, respectivamente, tramitados de acuerdo a la regulación adjetiva.

Además, si se examinan los artículos 13 y 14 de la misma ley, es posible reconocer que también habilita, de forma condicionada, el ejer- 
cicio de la potestad reglamentaria de ejecución para elaborar una regulación adjetiva, como lo es el procedimiento administrativo de decisión de resolución de calificación ambiental (RCA). Pero, a diferencia de los anteriores, este reglamento procedimental no se utiliza para crear regulación sustantiva, sino un permiso ambiental integrado, que es un acto administrativo de efecto individual.

El procedimiento administrativo para la adopción de la regulación ambiental adjetiva y sustantiva es tramitado por el MMA en sus etapas de iniciación e instrucción, y tiene una aproximación multisectorial, más notoria en la regulación sustantiva. Si bien, de acuerdo a la Ley 19.300, estas regulaciones se adoptan en ejercicio de la potestad reglamentaria de ejecución del Presidente de la República, no cabe duda de que dicho organismo cumple esencialmente una función reguladora, pero no administra, ni implementa, ni vigila el cumplimiento de esta regulación sustantiva, ni tampoco de la RCA.

Con esta distinción será más fácil comprender las funciones de cada organismo, y en particular aquéllas que los interconectan.

\subsection{MMA: organismo regulador}

Como ya se indicó, la regulación ambiental aplicable a los administrados es fundamentalmente de tipo sustantivo, pero, bajo el diseño de la Ley 19.300, ésta es el resultado de un procedimiento administrativo tramitado según la regulación adjetiva. De acuerdo a ese diseño, el artículo 70 letra n) de dicha ley indica que corresponde al MMA coordinar el procedimiento de generación de la regulación sustantiva, determinando los programas para su cumplimiento. Estos programas no parecen estar en la esfera de la vigilancia, el cumplimiento y la coerción, pues ello implica inmiscuirse en las competencias de programación que tiene la SMA, pero sí pueden referirse a mecanismos estructurales para planificarla, principalmente de índole presupuestaria.

En ese sentido, según el artículo 70 letra 1), el MMA debe participar en la elaboración de los presupuestos ambientales sectoriales, promoviendo su coherencia con la política ambiental nacional, para lo cual puede acordar indicadores de gestión asociados a presupuestos con el ministerio sectorial, y sujetos a aprobación de la Dipres. Este mecanismo es voluntario, tutelado desde esa dirección, y no ha sido utilizado desde el año 2010 hasta la fecha. 
Además, de acuerdo al artículo 70 letra o), corresponde al MMA interpretar administrativamente la regulación sustantiva, previo informe del o los organismos con competencia en la materia específica y de la SMA; además, podrá requerir a los jefes de los servicios y organismos con competencias en materia ambiental informes sobre los criterios utilizados por el respectivo organismo sectorial en la aplicación de esta regulación sustantiva. ${ }^{5}$

Se añade a esto que el artículo 72 letra f) indica que el Consejo de Ministros para la Sustentabilidad debe pronunciarse sobre la proposición de los proyectos de regulación adjetiva o sustantiva ambiental que, de aprobarse, se someterán a consideración del Presidente de la República. Esto demuestra que dichas regulaciones son esencialmente multisectoriales, y asumen que el MMA ha coordinado e instruido rigurosamente el procedimiento administrativo para adoptar la regulación sustantiva.

Pero, a efectos de esta investigación, lo más relevante es que nuestra regulación adjetiva establece que en dichos procedimientos administrativos se deben calcular los costos de vigilarla y hacerla cumplir, en los que necesariamente deberá incurrir la Administración. Así lo señalan expresamente el artículo 15 del DS n. ${ }^{\circ}$ 38/2012, del MMA, que establece el reglamento para la dictación de NCA y NE; y el artículo 9 del DS n. ${ }^{\circ}$ 39/2012, del MMA, que establece el reglamento para dictación de PPDA.

${ }^{5}$ Aquí ya se detecta un problema, pues la norma reconoce que hay varios organismos que deberían implementar, administrar o fiscalizar estas regulaciones, pero hoy casi no es así. A modo de ejemplo, y esto forma parte de un problema interpretativo de la Ley 20.417, todas las normas de emisión de procesos industriales están siendo administradas y fiscalizadas sólo por la SMA. En ese sentido, por ejemplo, el DS n. ${ }^{\circ}$ 13/2011, del MMA, norma de emisión para centrales termoeléctricas, artículo 7 indica: "corresponderá el control y fiscalización del cumplimiento... a la (SMA)"; y el DS n. ${ }^{\circ}$ 28/2013, del MMA, norma de emisión para fundiciones de cobre, artículo 11 indica: "corresponderá el control y fiscalización del cumplimiento del presente decreto a la (SMA)". En cambio, tratándose de normas de emisión de vehículos motorizados, las modificaciones no han excluido a los organismos sectoriales, como el DS n. ${ }^{\circ}$ 211/1991, del Ministerio de Telecomunicaciones y Transportes (MTT), norma de emisión para vehículos motorizados livianos, cuyo artículo 13 indica: “corresponderá la fiscalización... al (MTT)... sin perjuicio de las atribuciones que le correspondan a la (SMA)"; y el DS n. ${ }^{\circ} 55 / 1994$, del MTT, norma de emisión para vehículos pesados, cuyo artículo 13 indica: "la (SMA) fiscalizará la presente norma de emisión sin perjuicio de las atribuciones (del MTT)". 
No obstante, como demostraremos en la parte 3 de este documento, nuestro regulador ambiental se ha rehusado casi permanentemente a realizar un cálculo serio de estos costos, bajo lo cual subyace una condicionante estructural. En ese sentido, se debe tener presente que el éxito de la gestión política del MMA se mide principalmente según su productividad normativa.

\subsection{SEA: organismo coordinador de evaluación ambiental y emisor de permisos}

Antes indicamos que el artículo 13 de la Ley 19.300 ordena elaborar un reglamento adjetivo para la evaluación ambiental de proyectos. El organismo encargado de instruir el procedimiento administrativo para hacer dicha evaluación y aprobar o denegar la autorización ambiental de los proyectos es el SEA. Pero este organismo funciona bajo un sistema de toma de decisiones complejo.

De acuerdo a dicho diseño, según el artículo 81 letra a) de la Ley 19.300, el SEA administra el Sistema de Evaluación de Impacto Ambiental (SEIA), lo que se complementa con el artículo 8 inciso 5 de la misma ley, que indica que además tiene la potestad coordinadora sobre los organismos de la Administración involucrados en el mismo, para efectos de los permisos o pronunciamientos pertinentes. Esto se complementa con su potestad normativa del artículo 81 letra d) de la misma ley, que le permite uniformar los criterios, requisitos, condiciones, antecedentes, certificados, trámites, exigencias técnicas y procedimientos de carácter ambiental que establezcan los organismos competentes, relacionados con el SEIA.

Se añade a lo anterior que, según el artículo 81 letra g) de la misma ley, dicho servicio debe interpretar administrativamente las RCA, previo informe del o los organismos con competencia en la materia específica que participaron de la evaluación, del MMA y la SMA, según corresponda. ${ }^{6}$

${ }^{6}$ Esa misma norma indica que dicha potestad interpretativa está limitada, pues, si la RCA contuviese aspectos normados sometidos a las facultades de interpretación administrativa del organismo sectorial respectivo, el informe solicitado tendrá el carácter de vinculante. En todo caso, la ley tiene un error de referencia, pues indica que dicho informe es vinculante "para el ministerio en relación a esa materia", cuando en realidad lo es para el SEA. 
Pero el mismo artículo 8 inciso 1 indica que todos los permisos o pronunciamientos de carácter ambiental, que de acuerdo con la legislación vigente deban o puedan emitir los organismos de la Administración, respecto de proyectos o actividades sometidos al SEIA, serán otorgados a través de ese mismo sistema. Esto ratifica que se trata de un sistema de permisos ambientales integrados, en el que subsisten los denominados permisos ambientales sectoriales, en conjunto con la RCA. Por esto, el SEA incurre en costos de coordinación, al tener que intercambiar información con los organismos sectoriales, para efectos de la evaluación ambiental y de los permisos ambientales sectoriales (Hernández 2017, 15-19).

Además, la etapa de finalización del procedimiento y la de eventual revisión son igualmente complejas e, incluso, inexplicables. ${ }^{7}$ También se han producido situaciones delicadas en la evaluación de proyectos, que involucran aspectos interpretativos sobre las competencias legales de los organismos evaluadores, así como sus realidades presupuestarias y sus prioridades, como la que generó el reciente dictamen n. ${ }^{\circ}$ 19879/2017, de la Contraloría General de la República (CGR). ${ }^{8}$

${ }^{7} \mathrm{Si}$ el procedimiento de evaluación ambiental se desarrolla en el nivel regional, según el artículo 9 inciso 2 de la Ley 19.300, su etapa resolutiva se radica en una comisión de evaluación ambiental — predominantemente política, dada la integración que indica el artículo 86 de la misma ley-, pero en el nivel interregional se radica en el director ejecutivo del SEA — predominantemente técnico- Mas, inexplicablemente los recursos de reclamación contra estas decisiones se interponen, en caso de ingreso por Declaración de Impacto Ambiental (DIA), ante el director ejecutivo del SEA — predominantemente técnico-, y de ingreso por Estudio de Impacto Ambiental (EIA), ante el Comité de Ministros — predominantemente político-, como indican los artículos 20, 29 y 30 bis de la mencionada ley. Se tiene, entonces, que este procedimiento administrativo incluye varios grados de garantía del factor técnico, que en orden descendiente parecen ser: (i) proyecto interregional ingresado por DIA — donde sólo decide el director ejecutivo del SEA, incluso en una eventual fase recursiva - , (ii) proyecto regional ingresado por DIA - donde primero decide la comisión de evaluación, pero el director ejecutivo del SEA decide en la fase recursiva - , (iii) proyecto interregional ingresado por EIA — donde primero decide el director ejecutivo, pero el Comité de Ministros decide en la fase recursiva - y (iv) proyecto regional ingresado por EIA — donde primero decide la comisión de evaluación, y el Comité de Ministros decide en la fase recursiva一 . No hay explicación razonable para este diseño.

${ }^{8}$ Se trata de una disputa entre el SEA y la Superintendencia de Servicios Sanitarios, en la que la última informó a la primera que no participaría en la evaluación ambiental de proyectos que contemplen sistemas de tratamiento y disposición de 


\subsection{SMA: organismo coordinador de vigilancia y sancionador}

La SMA es el organismo fiscalizador, lo que se traduce en que está encargada de vigilar la observancia de permisos ambientales integrados y de regulación sustantiva, y de obtener cumplimiento a través de procedimientos sancionatorios o de la negociación de programas de cumplimiento. Sin embargo, éste también funciona bajo un sistema de toma de decisiones complejo, aunque estos problemas están mayormente limitados a la vigilancia.

El cumplimiento normativo es el estado de observancia de un sujeto en relación con una norma, con indiferencia de su motivación; en cambio, la aplicación normativa son las acciones destinadas a asegurar que el incumplimiento tendrá consecuencias negativas. Para la aplicación normativa son indispensables la vigilancia y la sanción, así como las estrategias intermedias que permitan que el sistema pueda ser manejado responsivamente, a través de los programas de cumplimiento, los planes de reparación, e inclusive el olvidado procedimiento de certificación de conformidad (Pinilla y Hernández 2016, 534-535).

Según el artículo 2 inciso 1 de la Ley Orgánica de la Superintendencia del Medio Ambiente (LOSMA), ${ }^{9}$ la SMA tiene por objeto ejecutar, organizar y coordinar el seguimiento y fiscalización de las RCA, los PPDA, las NCA y las NE, "cuando corresponda”. Los demás incisos del mismo artículo indican que los organismos sectoriales que cumplan funciones de fiscalización ambiental conservarán sus competencias y potestades de fiscalización, en todas aquellas materias e instrumentos

residuos líquidos de empresas que ella no fiscaliza por no ser concesionadas. El dictamen aplica el artículo 9 incisos 4 y 5 de la Ley 19.300, sosteniendo que la frase "sus respectivas competencias" no se limita al aspecto legal, sino que además incluye el aspecto técnico; por lo que, citando los principios de cooperación y coordinación, decide que la Superintendencia de Servicios Sanitarios (SISS) debe emitir su opinión técnica en el SEIA incluso respecto de proyectos que no fiscaliza. Esta decisión olvida que es la autoridad sanitaria la que tiene las competencias legales para autorizar sectorialmente y fiscalizar a estas empresas que proveen servicios sanitarios no concesionados. Cabría indagar los motivos por los cuales la autoridad sanitaria, teniendo la competencia legal, no tiene la competencia técnica para evaluar. Lo que subyace detrás de la inhibición de la SISS y de la autoridad sanitaria es la combinación de restricción presupuestaria y responsabilidad principal del organismo, que las obliga a priorizar tareas permanentemente y, en lo posible, traspasar responsabilidades, y eventuales costos políticos, hacia otros organismos.

${ }^{9}$ Contenida en el inciso segundo de la Ley 20.417 . 
que no sean de competencia de la SMA, y que éstos deberán adoptar y respetar todos los criterios que ésta establezca sobre la forma de ejecutar las actuaciones de fiscalización. La redacción de este artículo ha dado problemas, en particular si se examina en relación con el resto del articulado de esa ley.

Una interpretación sostiene que la competencia fiscalizadora de la SMA es exclusiva y excluyente (Fernández 2013, 128; Cannoni et al. 2015, 139; Bermúdez 2014, 433, 453-454; Bermúdez 2013, 440441; Riquelme et al. 2011, 244-245; Boettiger 2010, 447-448; Plumer 2013, 310; Mallea 2014: 139-140), aunque se reconoce la ambigüedad semántica de los artículos 2 y 35 de la LOSMA, con la frase "cuando corresponda", y que, para ciertos casos, como las normas de emisión de productos, hay inconvenientes para implementar dicha exclusividad (Bergamini et al. 2018, 174-177, 190). Otra interpretación sostiene que la competencia fiscalizadora de la SMA es parcialmente concurrente con la de los organismos sectoriales, que la SMA tiene una potestad de coordinación directiva sobre éstos a fin de planificar y uniformar el ejercicio de las potestades fiscalizadoras, y que en la regulación sustantiva hay que hacer diferenciaciones que resultan en que algunas de éstas ni siquiera sean fiscalizadas por la SMA (Hernández 2017, 26-32; Hernández 2018, 152).

La Contraloría ha adherido permanentemente a la primera interpretación, como lo refleja su reciente dictamen $90.184 / 2016,{ }^{10}$ basado en el dictamen $25.081 / 2013,{ }^{11}$ aun cuando ha tomado razón de decretos supremos que adoptan una posición contraria — como los que establecen normas de emisión de productos y planes de prevención y de des-

${ }^{10}$ Este dictamen señala que "es necesario efectuar una prevención en orden a que cuando se trate de almacenamiento de sustancias peligrosas que forme parte o que sirva de base para que un proyecto o actividad sea calificado favorablemente, en el marco del sistema de evaluación de impacto ambiental, la fiscalización corresponderá a la (SMA), sin perjuicio del encomendamiento de acciones que se realicen en la materia".

${ }^{11}$ Este dictamen señala que un organismo sectorial "sólo debe fiscalizar los instrumentos de gestión ambiental en comento, en la medida que esa Superintendencia le encomiende la ejecución de las inspecciones, mediciones y análisis que se requieran para el cumplimiento de los programas y subprogramas de fiscalización, para lo cual ha de ajustarse a los criterios que aquélla fije en relación a la forma de desempeñar tales labores", y que es necesario previamente la suscripción de convenios de encomendación de funciones. 
contaminación -; pero la segunda interpretación ha sido refrendada por la Corte Suprema, en sentencias de casación de las causas rol 38.340$2016^{12}$ y $15.549-2017^{13}$. Sin embargo, para mayor complicación de toda índole, una nueva interpretación ha surgido a partir de esta última sentencia, ${ }^{14}$ aplicada también en la sentencia de apelación de recurso de protección, causa rol 34.594-2017, ${ }^{15}$ y es que las competencias de la SMA no están limitadas a los instrumentos de gestión ambiental, sino que se expanden a toda materia de contenido ambiental. Según se adopte una u otra posición, la carga de trabajo diseñada para la SMA variará considerablemente.

Sin perjuicio de lo anterior, es indudable que algunos artículos de la LOSMA están redactados teniendo en cuenta la superposición de competencias fiscalizadoras, algo que ha sido reconocido, aunque finalmente interpretado en sentido de la exclusividad (Bermúdez 2014, 433,

${ }^{12}$ En su considerando $10^{\circ}$, señala que "la SMA tiene a su cargo la labor de fiscalización en materia ambiental, encontrándose facultada para realizarla directamente estableciendo programas de fiscalización, como asimismo puede determinar que esta labor la realice el órgano sectorial con competencia específica en la materia a fiscalizar, elaborando subprogramas de fiscalización".

${ }^{13}$ En su considerando $6^{\circ}$, señala que "la SMA tiene a su cargo la labor de fiscalización en materia ambiental, encontrándose facultada para realizarla directamente estableciendo programas de fiscalización, como también para determinar que esta labor sea realizada por el órgano sectorial con competencia específica en la materia a fiscalizar, elaborando subprogramas de fiscalización".

${ }^{14}$ En su considerando $8^{\circ}$, señala que la competencia fiscalizadora de la SMA "debe ser entendida en el contexto, más amplio, de la normativa destinada a cautelar el derecho a vivir en un medio ambiente libre de contaminación y, en consecuencia, sus atribuciones y facultades no pueden ser comprendidas como restringidas y limitadas, exclusivamente, a la fiscalización y sanción de las conductas transgresoras vinculadas con actividades que hayan sido sometidas al (SEIA)", y por tanto está obligada "a fiscalizar toda clase de actividades que puedan lesionar el medio ambiente, con independencia de si las mismas han sido sometidas previamente al (SEIA), puesto que, en la perspectiva del deber de protección del derecho a vivir en un medio ambiente libre de contaminación que recae sobre el Estado, sus funciones no se pueden ver constreñidas, de manera artificial, por una exigencia de esa clase".

${ }^{15}$ En su considerando $6^{\circ}$, señala que la SMA tiene competencias para "el debido control y supervisión de las Resoluciones de Calificación Ambiental, de las medidas de los Planes de Mantención y de los Planes de Manejo, entre otros, instrumentos todos que son aplicables a las empresas del rubro". Sin embargo, el primero de los planes que indica no existe en nuestro derecho positivo, y el segundo, aunque sí existe, se refiere expresamente a los contenidos en el artículo 42 de la Ley 19.300 , los que a la fecha nunca han sido dictados. 
453-454; Bermúdez 2013, 440-441). Pero además es indudable que dicha ley separa con enorme claridad entre seguimiento e inspección. Esta división es importante, porque también sirve para calibrar la carga de trabajo diseñada para la SMA.

El seguimiento es entendido como la obligación de monitoreo, registro y reporte que tiene un administrado hacia la Administración; es decir, genera información sobre su actividad que debe ser dirigida a esta última. El administrado aplica el principio quien contamina paga, pues a través de la regulación sustantiva no sólo se internalizan los costos sociales de contaminar — obligando al administrado a adoptar medidas mitigadoras de sus actividades contribuidoras de la contaminación o cobrándole un impuesto por esto último-, sino que también se internalizan los costos de obtener información para evaluar el cumplimiento normativo. Es decir, el administrado no sólo invierte para disminuir su contribución a la contaminación, sino que además para proveer los medios probatorios a la Administración para que evalúe el cumplimiento, y ésta sólo incurre en los costos de comprobar y procesar la información, y eventualmente de realizar acciones para obtener cumplimiento.

Esto es muy importante, porque a menudo se olvida que la empresa no sólo deberá decidir sobre invertir en relación con cierto grado de cumplimiento regulatorio, sino que también sobre la veracidad de lo que reporte, pues ni honestidad ni deshonestidad pueden presumirse (Heyes 1998, 55). Siendo así, como la mayor parte de la regulación ambiental contiene obligaciones de monitoreo, registro y reporte, los costos administrativos de comprobar y procesar información son muy altos $\mathrm{y}$, por tanto, la restricción presupuestaria resultará en la mayor necesidad de priorizar la revisión de ciertos informes, en detrimento del resto.

En cambio, en la inspección, es la Administración la que se desplaza a las instalaciones del administrado para revisarlas. De esta forma, el administrado debe permitir que se ingrese a su instalación y se realicen actividades materiales de constatación del estado y circunstancia de ésta y de sus alrededores. Es decir, la Administración obtiene los medios probatorios e incurre en los costos consiguientes.

Para auxiliar a ambas modalidades de constatación del cumplimiento están los requerimientos específicos de información, incluidos en el artículo 3 letras e) y m) de la LOSMA, y la citación a declarar, incluida en el artículo 29 de la misma ley, que obedecen ya a casos 
puntuales en los que se habrá detectado alguna situación sospechosa a través de seguimiento o inspección.

En ese sentido, el artículo 20 de la LOSMA indica que la ejecución de los programas y subprogramas de fiscalización sólo contempla las actividades de inspección, el análisis de la información obtenida en éstas y la adopción de las medidas que correspondan; es decir, se excluye el seguimiento. Incluso, el artículo 22 de la misma ley indica que la SMA ejecutará las inspecciones, mediciones y análisis necesarios para el cumplimiento de los programas y subprogramas de fiscalización, como también los encomendará a los organismos sectoriales, y que a estos efectos les impartirá directrices. Pero al asumir inspección y seguimiento, en una cuestionable interpretación de la ley, la SMA ha adquirido innecesariamente una carga de trabajo inmanejable.

Por otra parte, si se examinan los artículos 16 al 20, y 22 a 26 de la LOSMA, se comprueba que los organismos sectoriales son referidos como competentes. ${ }^{16}$ Desde luego, esta competencia no recae sobre toda la regulación o toda la RCA, sino sobre la parte sectorial. ${ }^{17}$ Esta superposición de competencias entre la SMA y los organismos sectoriales, que obedece a criterios de atribución diferentes, es aún más evidente si, tal como expresa la ley, los programas y subprogramas están

${ }^{16}$ El artículo 16 de la LOSMA indica que cada subprograma de fiscalización debe identificar el organismo sectorial competente, y el artículo 17 indica que los programas y subprogramas deben garantizar adecuadamente la participación de la SMA en la fiscalización, así como de los organismos sectoriales, resguardando la debida coordinación, evitando duplicidad de funciones y, de ser el caso, indicando los presupuestos sectoriales asignados según el artículo 70 letra 1) de la Ley 19.300, así como los indicadores de desempeño asociados. Como estos presupuestos sectoriales no existen, los organismos sectoriales hacen estimaciones de costos en la práctica.

${ }^{17}$ Por ejemplo, un relleno sanitario que cuenta con resolución de calificación ambiental (RCA) ha debido incluir en la normativa ambiental aplicable al DS n. ${ }^{\circ}$ 189/2005, del Ministerio de Salud, el Reglamento de Condiciones Sanitarias y de Seguridad Básicas en los Rellenos Sanitarios, cuyo artículo $2^{\circ}$ indica que corresponde a la autoridad sanitaria fiscalizar y controlar su cumplimiento. Además, el mismo organismo debió declarar su conformidad — en su parte ambiental — con la solicitud del permiso ambiental sectorial (PAS) mixto del artículo 141 del DS n. ${ }^{\circ}$ 40/2012, del MMA, Reglamento del SEIA, para la construcción, reparación, modificación y ampliación de rellenos sanitarios. En este caso, la autoridad sanitaria determinó parte del contenido de la RCA; por tanto, es lógico que fiscalice ese mismo contenido, bajo la coordinación directiva de la SMA, y que no fiscalice ningún otro contenido que corresponda a otro organismo. 
limitados a actividades de inspección, y no a la revisión de informes de seguimiento. Además, la posición de coordinación directiva de la SMA sobre los organismos sectoriales se ratifica en el artículo 3 letra e), aun cuando desde una perspectiva política sea difícil requerir en términos perentorios a los organismos sectoriales.

Por último, y para aumentar la complejidad, también hay dos posiciones interpretativas respecto del artículo 35 de la LOSMA. Si bien dicha norma es clara al indicar que la potestad sancionatoria corresponde exclusivamente a dicho organismo, al describir algunos tipos relacionados con regulación sustantiva, usa nuevamente la frase "cuando corresponda", lo que trae como resultado que aquí también la exclusividad se diluya (Hernández 2018, 154-155).

\subsection{Inequidad presupuestaria y funciones asignadas}

Como vimos, el diseño organizativo de nuestra gobernanza ambiental establece la separación de funciones, donde el MMA tiene preeminencia política total sobre los otros dos organismos. Aunque parezca mezquino, la severa restricción presupuestaria de las dos organizaciones políticamente subordinadas al MMA, más la necesidad de ésta de mostrar nueva regulación obligan a los tres organismos a practicar el "juego de la culpa", a pesar de que el objetivo de la reforma ambiental es que no suceda.

Para introducir la inequidad financiera, se pueden observar las series presupuestarias del sector ambiental desde 2014 a 2018 en la tabla 1, donde se expresa la proporción numérica de funcionarios y la proporción porcentual de recursos financieros entre el MMA, el SEA y la SMA.

Al revisar la cuenta pública de 2016, la SMA señaló que debía controlar más de 11.000 unidades fiscalizables, y que, tras revisar 1.803 expedientes, agrupó 808 infracciones en 149 procedimientos sancionatorios, y descartó 926 por falta de mérito (SMA 2017). No obstante, también señaló que se había ingresado hasta 2016 un total de 6.118 denuncias ciudadanas, mientras que un estudio sobre el tema, que sorprendentemente propone incrementar las posibilidades de denuncias ciudadanas, determinó que el 86 por ciento de éstas estaría aún en proceso de investigación (Cordero et al. 2017, 28, 72-77). Pero a esto debe añadirse el cúmulo de informes de seguimiento no revisados. De hecho, el incendio del relleno sanitario Santa Marta reveló que los informes de seguimiento de dicha instalación no se habían revisado desde 2013 (CGR 2016, 35, 
42; Hernández 2017, 9-14). En ese sentido, si bien la SMA puede ordenar la estandarización de reportes de seguimiento de tipo numérico para automatizar su procesamiento, ello no es posible para los demás reportes, que debe leer y analizar, consumiendo horas-funcionario (HF).

Tabla 1. SERIES PRESUPUESTARIAS DEL SECTOR AMBIENTAL DESDE 2014 A 2018 , EN PROPORCIÓN DE FUNCIONARIOS Y RECURSOS FINANCIEROS

Funcionarios

\begin{tabular}{|c|c|c|c|}
\hline 2018 & 513 & 339 & 200 \\
\hline 2017 & 510 & 317 & 183 \\
\hline 2016 & 444 & 311 & 152 \\
\hline 2015 & 441 & 311 & 128 \\
\hline 2014 & 405 & 296 & 107 \\
\hline
\end{tabular}

Recursos financieros

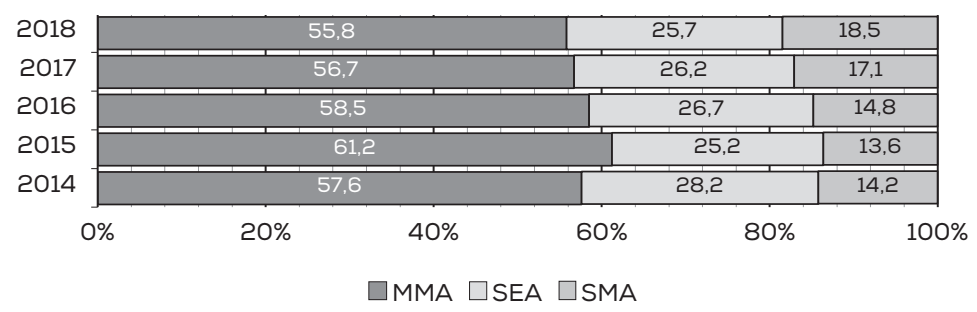

La capacidad de procesamiento de la SMA, que ya estaba sobrepasada, inevitablemente se ha resentido más con la aprobación de los nuevos planes y normas, en particular el plan de la Región Metropolitana. Otra causa es la operativización del artículo 8 de la Ley 20.780 - que aprueba la reforma tributaria_, que hace a dicho organismo responsable de la fiscalización y determinación del hecho gravado en el impuesto a emisiones de fuentes estacionarias, y del artículo 38 de la Ley 20.920, sobre gestión de residuos, responsabilidad extendida del productor y fomento al reciclaje, que también lo hace responsable de su fiscalización y sanción.

Nuevamente, la SMA enfrentará más restricción presupuestaria y costo de oportunidad. Pero, la Contraloría insiste en que debe cumplir los principios de celeridad, responsabilidad, eficacia y eficiencia. Además, el MMA la exhorta a que debe fiscalizar más regulaciones e incluso, como hemos visto, nuevas leyes - impuestos a fuentes estacionarias y la responsabilidad extendida del productor - aumentan su rango de 
labores. Pero ambos organismos olvidan que, entre 2017 y 2018, la SMA aumentará su capacidad de gestión en apenas 33.864 HF. Como veremos en la siguiente parte, sólo la fiscalización del plan de la Región Metropolitana le consumirá $58.750 \mathrm{HF}$.

En 2016, según la definición estratégica presupuestaria de la SMA (Dipres 2015a), el 61 por ciento de sus recursos se destinan a fiscalización y sanción, por lo que es posible proyectar que 95 de sus 152 funcionarios asumen tal labor. Ese mismo año, según la misma definición presentada por el MMA (Dipres 2015b), el 42 por ciento de sus recursos se destinan a regulación ambiental, por lo que es posible proyectar que 180 de sus 444 funcionarios asumen tal labor.

Siendo así, hoy tenemos a casi el doble de los funcionarios dedicados a generar regulación ambiental en el MMA que los dedicados a hacerla cumplir en la SMA, lo que es un evidente sinsentido. ${ }^{18}$ Nuestra posición es que estamos ante un problema estructural de diseño institucional, que permite a los directivos del organismo con predominio político desarrollar estrategias para reclamar crédito político en el corto plazo. Esto se suma a un problema de incorrecta definición de prioridades presupuestarias.

En resumen, nuestro organismo regulador ambiental es el MMA, y su éxito político se mide por cuánto avanza en la adopción de regulación sustantiva o de proyectos legislativos. Por ello, su principal producto estratégico para fines presupuestarios es la regulación ambiental (Dipres 2015b). Pero ni implementa, ni administra, ni controla esta última, por lo que tiene incentivos para ser indiferente respecto de la carga de trabajo de los organismos que deban cumplir esa función.

El organismo coordinador de evaluación ambiental y emisor de permisos es el SEA, y su éxito político se mide por cuántos proyectos se conforman con su decisión, cuánto demora la tramitación y cuántos proyectos mantienen su calificación luego de las reclamaciones judiciales; por eso su principal producto estratégico para fines presupuestarios es la evaluación ambiental (Dipres 2015c). Pero los proyectos aprobados no son fiscalizados por el SEA, por lo que tiene incentivos para ser indiferente respecto de la carga de trabajo de los organismos que deban cumplir esa función.

${ }^{18}$ Desde luego, hay que prevenir que al MMA le aplica el régimen remuneratorio EUS (escala única de sueldos), regido fundamentalmente por el DL 249/1973, y a la SMA el régimen remuneratorio EOF (escala de organismos fiscalizadores), regido fundamentalmente por el DL 3351/1981, la que contempla una asignación especial de fiscalización, que incrementa considerablemente las remuneraciones de la EOF en comparación con la EUS. De acuerdo a ello, la hora-funcionario para el mismo grado es más cara en la EOF que en la EUS. 
El organismo coordinador de vigilancia y sancionador es la SMA, ubicado al final de la cadena. Mide su éxito político por cuántos administrados han sido vigilados, a cuántos se les ha detectado incumplimiento y cuántos han vuelto al cumplimiento por aplicación de sanciones o de programas de cumplimiento. Por eso sus principales productos estratégicos para fines presupuestarios son la fiscalización ambiental y el sistema de sanciones y multas (Dipres 2015a). ${ }^{19}$

Así, la determinación correcta y sincera de los costos para fiscalizar la regulación sustantiva - tanto por inspección como por seguimiento, tanto para tramitar procedimientos sancionatorios como para obtener el cumplimiento efectivo de las sanciones - es determinante para predecir el comportamiento y rendimiento de la SMA. Enseguida abordaremos ese tema.

\section{COSTOS DE CUMPLIMIENTO EN EL ANÁLISIS GENERAL DE IMPACTO ECONÓMICO Y SOCIAL: (IN)SINCERIDAD}

Para demostrar cómo, en nuestra opinión, el MMA ha ignorado o subestimado los costos de fiscalización y sanción de la regulación sustantiva, revisaremos los Análisis General de Impacto Económico y Social -AGIES - emitidos por dicho organismo desde 2011, dentro de los procedimientos administrativos para adopción de regulación sustantiva. Así también, revisaremos las comunicaciones enviadas por la SMA al MMA en relación con los mismos. Además, dividiremos el análisis

${ }^{19}$ Estudios sobre eficacia de la acción regulatoria, para efectos de simplificación, asumen que estas tres funciones están reunidas en una sola agencia, uniendo la emisión de regulación y permisos con su vigilancia. En ese sentido, se asume que la agencia tiene discrecionalidad para establecer las reglas y un presupuesto limitado que restringe el número de actividades de control de cumplimiento que puede hacer, por lo que debería distribuirlo óptimamente (Garvie y Keeler 1994, 144). Pero una variable que también debe incluirse en la distribución óptima es el estándar probatorio, pues determinará cuánta información será necesaria para la toma de decisiones asociadas a detección de infracciones y a su manejo por vía negociada — a través de programas de cumplimiento - o adversarial —a través del procedimiento sancionatorio-. Esto ya se ha explorado, aunque no centrado en el dilema presupuestario de la agencia, revelando que, a mayor exactitud en la determinación fáctica de la infracción, la aplicación de sanciones será menos aleatoria, por lo que generará más disuasión (Posner 1999, 1483). Por tanto, un mayor estándar probatorio hace incurrir a la Administración en mayor gasto, de ahí que la discusión acerca de si se trata de estándares de prueba preponderante, o clara y convincente, o más allá de toda duda razonable, no solo tiene consecuencias jurídicas, sino que también presupuestarias. 
por tipo de regulación; esto es, normas de calidad ambiental, normas de emisión y planes de prevención o de descontaminación.

Como hemos señalado antes, los reglamentos procedimentales para la adopción de esta regulación están contenidos en el DS n. ${ }^{\circ}$ 38/2012 — para la dictación de normas de calidad y de emisión - y en el DS n. ${ }^{\circ}$ 39/2012 — para la dictación de planes de descontaminación—, ambos del MMA. Los dos decretos responden a la definición y adopción de un programa de regulación ambiental bianual, en el que además se establecen criterios de sustentabilidad y prioridades programáticas en materia de políticas, planes y programas.

Ambos reglamentos procedimentales tienen etapas similares, las que resumidamente son: (i) elaboración del anteproyecto de regulación en un plazo de doce meses de publicada en el Diario Oficial la resolución que inicia el procedimiento normativo, dentro del cual se incluye el desarrollo o recopilación de estudios científicos, así como la preparación de dos documentos de apoyo —-Análisis Técnico y AGIES -; (ii) consulta del anteproyecto en un plazo de 60 días de publicado en el Diario Oficial el extracto de resolución que aprueba el anteproyecto, y que incluye la consulta al Consejo Consultivo del MMA y al público general; (iii) análisis de observaciones de la consulta y elaboración del proyecto definitivo, en un plazo de 120 días desde el término de la etapa previa; (iv) sometimiento del proyecto definitivo a consideración del Consejo de Ministros para la Sustentabilidad, y, finalmente, (v) sometimiento a consideración del Presidente de la República para el ejercicio de su potestad reglamentaria. Este procedimiento administrativo, como todos, genera documentación que debe contenerse en un expediente físico, insertada en orden correlativo a su ingreso, pero además debe mantenerse un expediente electrónico, para permitir su consulta expedita por todos los interesados.

\subsection{Los costos de fiscalización en las normas de calidad ambiental}

En las normas atmosféricas, para la revisión de la normas de calidad ambiental (NCA) primaria de MP10 no se indicaron los costos de fiscalización en los AGIES de fojas $1009^{20}$ y fojas $1046 .{ }^{21}$ No obs-

\footnotetext{
${ }^{20}$ Véase https://goo.gl/kt4Uim.

${ }^{21}$ Véase https://goo.gl/Zj8M3h.
} 
tante, la SMA advirtió al MMA que "no ha sido consultada sobre los costos asociados a todas las actividades que implican el seguimiento y control de los monitoreos de calidad del aire", y añadió que "sin esta información no sólo es cuestionable la estimación de costos del AGIES, afectando así la fundamentación de la norma (...) sino que además hace imposible solicitar el presupuesto para desarrollar estas tareas". ${ }^{22}$ Esta comunicación no se incluyó en el expediente electrónico, que, como señalamos, es un requerimiento establecido a nivel reglamentario.

De forma similar, para la revisión de la NCA primaria de $\mathrm{SO}_{2}$ no se indicaron los costos de fiscalización en los AGIES de fojas $703,{ }^{23}$ fojas $1204^{24}$ y fojas $1230 .{ }^{25}$ No obstante, la SMA advirtió al MMA que "es imprescindible precisar que el alcance de la fiscalización de la norma de calidad se refiere exclusivamente a las estaciones de interés del MMA para efectos de política pública (...) lo que además permite conocer el número exacto de estaciones de monitoreo y así solicitar fundadamente el presupuesto necesario para su fiscalización". ${ }^{26}$ Esta comunicación tampoco se incluyó en el expediente electrónico.

En las normas hídricas el panorama no es muy distinto. Para la NCA secundaria del río Aconcagua - expediente electrónico sin foliación—, ${ }^{27}$ el AGIES ${ }^{28}$ estimó el costo de fiscalización en $\cong 3.000 .000$ de pesos anuales (valor 2017), adicionales a los que ya gasta la Dirección General de Aguas. No obstante, la SMA advirtió al MMA que, "con relación a los costos, y a fin de evitar una subestimación que frustre a futuro una implementación de la norma, hacemos presente que la situación actual no se encuentra descrita suficientemente en el AGIES", añadiendo que "una adecuada descripción de la situación actual permite proyectar fundadamente el flujo de costos totales durante la implemen-

22 Of. Ord. n. ${ }^{\circ} 1791 / 2017$, obtenido por solicitud de transparencia n. ${ }^{\circ}$ AW003T0001938.

${ }^{23}$ Véase https://goo.gl/PMr1Pe.

${ }^{24}$ Véase https://goo.gl/J3LgfF.

${ }^{25}$ Véase https://goo.gl/BfgP5x.

26 Of. Ord. n. ${ }^{\circ} 1577 / 2017$, obtenido por solicitud de transparencia n. ${ }^{\circ}$ AW003T0001938.

${ }^{27}$ De acuerdo al artículo 18 de la Ley 19.880 y los artículos 8 del DS n. ${ }^{\circ}$ 38/2012 y 5 del DS n. ${ }^{\circ}$ 39/2012, ambos del MMA, debe guardarse un orden riguroso de ingreso y egreso de documentos en la conformación del expediente administrativo, y su principal garantía es la foliación.

${ }^{28}$ Véase https://goo.gl/fRZhUV. 
tación de la norma", pues, "con ello, es posible tener claro el costo real de todos estos monitoreos y fortalecer la implementación de la norma". Agrega que sólo para revisión de parámetros y preparación de informes deberá destinar $\cong 17.000 .000$ de pesos anuales, y que, por tanto, se estima "relevante contar con un informe de (Dipres) que comprometa la asignación de recursos para la implementación de esta norma, considerando a todos los organismos públicos involucrados". ${ }^{29}$ Esta comunicación tampoco se ha incluido en el expediente electrónico.

Por su parte, para la NCA secundaria del río Valdivia, el AGIES de fojas $3377^{30}$ estimó el costo de fiscalización en $\cong 8.000 .000$ de pesos anuales (valor 2014); para el río Rapel —expediente electrónico sin foliación-, el AGIES ${ }^{31}$ lo estimó en $\cong 9.000 .000$ de pesos anuales (valor 2016); para el río Maipo, el AGIES de fojas $2251^{32}$ lo estimó en $\cong 33.000 .000$ de pesos anuales (valor 2013); para el río Biobío, el AGIES de fojas $976^{33}$ lo estimó en $\cong 43.000 .000$ de pesos anuales (valor 2013), y el de fojas $1113^{34}$ en $\cong 17.000 .000$ de pesos anuales (valor 2014). En ninguno de ellos existe constancia de comunicación al respecto desde la SMA, incluida o no en el expediente electrónico.

Sin embargo, tras la sentencia del Tercer Tribunal Ambiental que anuló la NCA secundaria del río Valdivia, ${ }^{35}$ el AGIES de fojas $3563^{36}$ estimó costos por $\cong 80.000 .000$ de pesos anuales (valor 2017) y que la SMA utilizará $\cong 364 \mathrm{HF}$ anuales, pero advirtió que estos "no son en la realidad costos adicionales para el Estado, ya que no es práctica habitual la contratación de personal nuevo, sino que se añade a la carga laboral actual de los funcionarios del servicio correspondiente". Esto último es muy importante, porque se reconoce abiertamente que la nueva regulación hará incurrir a estos organismos en costos de oportunidad, pues para asumir la nueva carga de trabajo deberán dejar de hacer tareas que estaban haciendo.

29 Of. Ord. n. ${ }^{\circ} 2127 / 2017$, obtenido por solicitud de transparencia n. $^{\circ}$ AW003T0001938.

${ }^{30}$ Véase https://goo.gl/2mgbZf.

${ }^{31}$ Véase https://goo.gl/rGkCGi.

32 Véase https://goo.gl/jRLXYi, descomprimir y revisar documento 22252262.

${ }^{33}$ Véase https://goo.gl/dtWLxe.

${ }^{34}$ Véase https://goo.gl/yExjxu.

${ }^{35}$ Causa rol R-25-2016, sentencia de 29 de septiembre de 2016.

${ }^{36}$ Véase https://goo.gl/Xbz4hD. 


\subsection{Los costos de fiscalización en las normas de emisión}

En el caso de las normas de emisión (NE) de productos, en particular de ruidos en buses de locomoción colectiva urbana y rural, el AGIES de fojas $312^{37}$ no estimó costo de fiscalización alguno, aunque indicó que dicha norma sólo la fiscaliza el Ministerio de Telecomunicaciones y Transportes (MTT), lo que contradice el artículo 7 de dicha norma, que indica que también fiscaliza la SMA. De forma similar, para la NE de motocicletas - expediente electrónico sin foliación- el AGIES $^{38}$ no estimó costos de fiscalización para la SMA, aunque su artículo 5 tiene una cláusula de fiscalización idéntica a la anterior.

En la revisión de la NE de opacidad para vehículos en uso, el AGIES de fojas $16^{39}$ no estimó costos de fiscalización, lo que resulta comprensible porque su artículo 7 mantiene correctamente su fiscalización en Carabineros de Chile e inspectores fiscales y municipales. De igual forma, en la revisión de la NE de NOx para vehículos en uso - expediente electrónico sin foliación- el AGIES ${ }^{40}$ tampoco estimó estos costos, lo que resulta comprensible porque su artículo 8 mantiene correctamente su fiscalización en el MTT, a través de las plantas de revisión técnica concesionadas.

Respecto de la NE de ruido para vehículos motorizados medianos, livianos y motocicletas, el AGIES de fojas $345^{41}$ estimó el costo inicial de fiscalización en $\cong 2.292 .000 .000$ de pesos anuales (valor 2012), y los costos anuales en $\cong 58.000 .000$ de pesos (valor 2012), para el Centro de Control y Certificación Vehicular del MTT. Pero, a pesar de que su artículo 7 tiene una cláusula de fiscalización idéntica a las dos primeras, donde tienen competencias tanto el MTT como la SMA, no se estimó ningún costo alguno para esta última.

Acerca de la revisión de la NE para vehículos motorizados pesados, el AGIES de fojas $79^{42}$ estimó el costo de fiscalización inicial en $\cong 104.000 .000$ de pesos (valor 2012) para equipamiento de las plantas

\footnotetext{
${ }^{37}$ Véase https://goo.gl/cjHn5o.

38 Véase https://goo.gl/KoNMmb.

${ }^{39}$ Véase https://goo.gl/cN2L6u.

${ }^{40}$ Véase https://goo.gl/Rv8tVE.

${ }^{41}$ Véase https://goo.gl/X5Ndt6.

${ }^{42}$ Véase https://goo.gl/ZD1bWv.
} 
de revisión técnica concesionadas, pero a pesar de que el artículo 13 indica que también fiscaliza la SMA, no se estimó costo alguno para ésta.

Por su parte, para la NE para grupos electrógenos, que está actualmente en elaboración y aún no posee su AGIES, la SMA logró establecer una mesa de trabajo para diseñar los esquemas de control de la normativa. Allí sostuvo que carece de personal especializado ${ }^{43}$ y que la Superintendencia de Electricidad y Combustibles debería estar a cargo de su control, ${ }^{44}$ aunque el MMA insistió en que debe hacerlo la SMA. ${ }^{45}$

En cuanto a la NE para vehículos fuera de ruta - expediente electrónico sin foliación-, el AGIES ${ }^{46}$ no indicó los costos de fiscalización, a pesar de que la propuesta indica que tal función recaerá en la SMA. Pero dicho organismo advirtió al MMA que el diseño institucional considera que ella "responde al control de 'normas de proceso'; esto es, aquellas que regulan las emisiones durante el funcionamiento de industrias y establecimientos y, por ello, se establece un control periódico de las fuentes emisoras por medio de mediciones de las descargas de contaminantes al medio ambiente", y que "carece de personal técnico que pueda revisar los 'certificados de origen' que se presenten en cumplimiento de la norma de emisión". ${ }^{47}$ Esta comunicación tampoco se ha incluido en el expediente electrónico.

Por su parte, en el caso de las NE de procesos, en la tramitación de aquella para calderas y procesos de combustión, el AGIES de fojas $493^{48}$ estimó costos de fiscalización por inspección en $\cong 106.000 .000$ de pesos anuales (valor 2017). Sin embargo, la SMA advirtió nuevamente al MMA sobre estas estimaciones, indicando que la norma propuesta "genera importantes costos para el control y seguimiento de las fuentes emisoras reguladas por estos instrumentos", dada "la falta de uniformidad en los límites de emisión aplicables y en la frecuencia de los reportes de mediciones". Señaló, además, que el AGIES tiene errores porque, aunque éste advierta que para su cálculo "sólo fue considerada la fiscalización en las comunas que no cuentan con un Plan de Descontaminación Atmosférica

\footnotetext{
${ }^{43}$ Véase https://goo.gl/CGfKLM.

${ }^{44}$ Véase https://goo.gl/qtF9gD.

${ }^{45}$ Véase https://goo.gl/Ly5CzE.

${ }^{46}$ Véase https://goo.gl/YhQStz.

47 Of. Ord. n. ${ }^{\circ}$ 250/2017, obtenido por solicitud de transparencia n. ${ }^{\circ}$

${ }^{48}$ Véase https://goo.gl/i5oR4k.
} AW003T0001938. 
(PDA), debido a que en el caso de las comunas que ya cuentan con dicho instrumento dichos costos fueron considerados en el plan respectivo", se le ha hecho presente repetidamente al MMA, "en los oficios 167/2015, 693/2015, 1059/2015, 1222/2015, 1288/2015, 66/2016, 614/2016, 759/2016, 1002/2017, 1643/2017, [que] (...) no ha considerado los costos efectivos de fiscalización y sanción en los AGIES correspondientes de dichos instrumentos", y que el costo de fiscalización "no considera los costos administrativos asociados al control y seguimiento de fuentes fijas, especialmente tratándose de mediciones continuas, ni tampoco los procedimientos sancionatorios que se cursen como respuesta a las infracciones constatadas". Así, le comunicó al MMA una estimación de costos de $\cong 2.500 .000 .000$ de pesos anuales, y advirtió que "solicitamos que junto a la rectificación de los costos de fiscalización de esta norma se solicite un informe a la Dirección de Presupuestos donde asegure la disponibilidad presupuestaria requerida para su implementación". ${ }^{49}$ Esta comunicación tampoco se ha incluido en el expediente electrónico.

De forma similar, para la revisión de la NE de residuos industriales líquidos a aguas marinas y continentales superficiales, el AGIES de fojas 5.042 ${ }^{50}$ no estimó costos de fiscalización; para la NE de fundiciones, el AGIES de fojas $746^{51}$ tampoco lo hizo; para la revisión de la NE de celulosas, el AGIES de fojas $990^{52}$ no los calculó, y para la NE de termoeléctricas, en el AGIES de fojas $2019^{53}$ ocurrió lo mismo.

\subsection{Los costos de fiscalización en los planes de prevención y de descontaminación ambiental}

Respecto de los Planes de Prevención y Descontaminación Atmosférica (PPDA), cabe destacar que, por la diversidad de medidas que pueden incluir, es aquí quizá donde puede aumentar muchísimo más la carga de trabajo para la SMA. Como veremos enseguida, en los últimos años el organismo fiscalizador ha sido extremadamente activo señalando estas circunstancias.

49 Of. Ord. n. ${ }^{\circ} 2145 / 2017$, obtenido por solicitud de transparencia n. $^{\circ}$ AW003T0001938.

${ }^{50}$ Véase https://goo.gl/MbzGDL.

${ }^{51}$ Véase https://goo.gl/hn3QoN.

${ }^{52}$ Véase https://goo.gl/zFaoKM.

${ }^{53}$ Véase https://goo.gl/kwbrxr. 
Para la propuesta de plan de Los Ángeles, el AGIES de fojas $152^{54}$ no calculó costos de fiscalización, aunque en la actualización del informe de fojas $322^{55}$ es posible ver una tabla que indica costos de $\cong 478.000 .000$ de pesos anuales (valor 2016), entre fiscalización residencial e industrial, aun cuando su artículo 76 establece que la fiscalización será efectuada por la SMA o por los organismos sectoriales. En todo caso, la SMA advirtió al MMA que el AGIES de fojas 152 "ha omitido considerar los costos asociados al seguimiento y control de las medidas del plan por parte de ésta (SMA)", y le recordó que "dentro de las variables de cumplimiento normativo se encuentra el nivel de fiscalización y sanción... por lo tanto, un determinado nivel de cumplimiento se encontrará asociado a un determinado nivel de fiscalización y sanción". Así, "es fundamental incorporar en el AGIES la capacidad operativa actual de la SMA y, si es el caso, asegurar la entrega de mayores recursos para alcanzar los niveles de cumplimiento normativo en los cuales se sustentan los beneficios proyectados". 56

Para la propuesta de plan de Curicó también hay una comunicación de la SMA que advierte acerca de la necesidad de estimar sus costos de fiscalización, en un tenor idéntico al anterior ${ }^{57}$, por lo que el AGIES de fojas $1522^{58}$ los estimó en $\cong 64.000 .000$ de pesos anuales (valor 2017), y el AGIES de fojas $2137^{59}$ los reestimó en $\cong 85.000 .000$ de pesos anuales (valor 2017).

La propuesta de plan del Gran Concepción también calculó estos costos, aunque sin consolidarlos. En el AGIES de fojas $336,{ }^{60}$ para fuentes industriales indicó que se duplicarían las inspecciones, lo que estimó en $\cong 5.000 .000$ de pesos anuales (valor 2017), mientras que para fuentes domiciliarias los estimó en $\cong 16.000 .000$ de pesos anuales (valor 2017); pero, el AGIES de fojas 526 reestimó costos totales por $\cong 103.000 .000$ de pesos anuales (valor 2017). ${ }^{61}$ En todo caso, la SMA le

${ }^{54}$ Véase https://goo.gl/3JMDk5.

55 Véase https://goo.gl/LrLDnK.

56 Of. Ord. n. ${ }^{\circ} 1357 / 2016$, obtenido por solicitud de transparencia n. ${ }^{\circ}$ AW003T0001938.

${ }^{57}$ Véase https://goo.gl/v8Z2G3.

${ }^{58}$ Véase https://goo.gl/6eNku6.

${ }^{59}$ Véase https://goo.gl/QNUyUe.

${ }^{60}$ Véase https://goo.gl/SdTtNE.

${ }^{61}$ Véase https://goo.gl/bDurJQ. 
recordó al MMA que "es necesario incorporar dentro del procedimiento de elaboración de planes y normas un ítem que considere los gastos que implica (...) ampliar el universo de sujetos fiscalizados como consecuencia de la aprobación de dichos instrumentos", ya que en el AGIES "no se explica la estimación de los costos asociados al seguimiento y control de las medidas del plan", y que, "en caso de que los beneficios dependan de un cumplimiento del 100 por ciento de las fuentes reguladas, se requerirá un número de actividades de fiscalización y sanción con una cobertura anual importante de las fuentes afectas, el cual razonablemente pueda sustentar un nivel de cumplimiento cercano al 100 por ciento". 62

Pero donde probablemente más se aprecia la complejidad del asunto es en la propuesta de revisión del plan de la Región Metropolitana, hoy vigente. El AGIES de fojas $338^{63}$ no estimó los costos de fiscalización, y, aunque no se incluyó en el expediente electrónico, la SMA advirtió al MMA desde los inicios de su tramitación el severo problema que enfrentaría con un plan emblemático como éste. El problema radicaría en que el modelo de fiscalización "adolece de una serie de debilidades (...) en particular, se puede mencionar la figura de los subprogramas (...) ya que en la medida que no exista en la Ley de Presupuestos una glosa para fiscalización ambiental, hace al menos incierto el control efectivo de los sujetos regulados". También le informó que, de mantenerse la interpretación de la Contraloría respecto de la exclusividad de las competencias fiscalizadoras y sancionadoras de la SMA, sólo por efecto de la restricción vehicular y el plan de gestión de tránsito - medidas incluidas en el plan entonces vigente - "se manejaría un total de 360.000 infractores", por lo que "se necesitarían 511 funcionarios a dedicación exclusiva para la tramitación de dichos procedimientos", ${ }^{64}$ lo que implicaría un presupuesto adicional de $\cong 16.350 .000 .000$ de pesos anuales (valor 2015). ${ }^{65}$

62 Of. Ord. n. ${ }^{\circ} 1643 / 2017$, obtenido por solicitud de transparencia n. ${ }^{\circ}$ AW003T0001938.

${ }^{63}$ Véase https://goo.gl/dj6m5e.

${ }^{64}$ Of. Ord. n. ${ }^{\circ} 1288 / 2015$, obtenido por solicitud de transparencia n. ${ }^{\circ}$ AW003T0001938.

${ }^{65}$ Cálculo en base a $1.992 \mathrm{HF}$ anuales por funcionario, con la HF valorizada en $\cong 16.000$ de pesos. 
Pero, incluso cuando se adoptó la interpretación propuesta, contraria a la exclusividad de competencias, en abierta contradicción con los dictámenes de Contraloría, y se publicó el AGIES de fojas 338, la SMA comunicó al MMA que para los presupuestos de 2017 a 2021

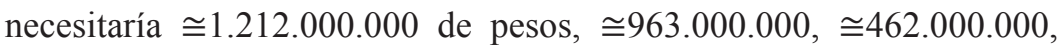
$\cong 820.000 .000 \mathrm{y} \cong 742.000 .000$ de pesos, respectivamente por cada año. Advirtió que el AGIES "ha omitido considerar los costos asociados al seguimiento y control de las medidas del plan por parte de esta (SMA)", y que "en la página 56 del AGIES se encuentra la única mención a los costos de fiscalización, pero se refiere sólo a tres servicios sectoriales que participarán en la implementación del plan (...) según datos históricos, sin referencia ni a los costos asociados al ejercicio de la potestad sancionatoria ni al nivel de cumplimiento normativo alcanzado con ese presupuesto". Así, "se califica el costo para la Administración como despreciable en relación a los beneficios esperados", pero que, a pesar de esto, "se observa que el cálculo de los beneficios estimados se sustenta en base a proyecciones de reducción de emisiones logradas a partir del cumplimiento efectivo de las medidas". ${ }^{66}$ Esto se traduce en que la SMA necesitaría $58.750 \mathrm{HF}$ anuales adicionales y, por tanto, 30 nuevos funcionarios a dedicación exclusiva para poder obtener el nivel de cumplimiento que asume el AGIES. ${ }^{67}$ Esta comunicación tampoco aparece en el expediente electrónico. A pesar de lo anterior, aunque de forma explicable bajo el problema de diseño institucional que hemos detectado, en el AGIES de fojas $639^{68}$ del plan de la Región Metropolitana, el MMA reafirmó que los costos de fiscalización serían de $\cong 130.000 .000$ de pesos (valor 2016), excluyendo los costos de la SMA, los que finalmente no se indicaron.

Para el plan de O'Higgins, el AGIES de fojas $1903^{69}$ indica que para la estimación de beneficios "se asume 100 por ciento de cumplimiento de las medidas, lo que demanda una fiscalización efectiva",

66 Of. Ord. n. ${ }^{\circ} 759 / 2016$, obtenido por solicitud de transparencia n. ${ }^{\circ}$ AW003T0001938.

${ }^{67}$ Cálculo en base a $1.992 \mathrm{HF}$ anuales por funcionario, con la HF valorizada en $\cong 16.000$ de pesos. Requerimiento adicional de presupuesto promedio de $\cong 940.000 .000$ de pesos anuales para los años 2017 a 2021 .

${ }^{68}$ Véase https://goo.gl/UndKdT.

69 Véase https://goo.gl/7z9ZFA, https://goo.gl/1s5Pn9 y https://goo.gl/jHs$5 \mathrm{~kW}$. 
cuyos costos estima en $\cong 75.000 .000$ de pesos anuales, sin indicar quién fiscaliza, ni cómo se obtuvo ese valor.

Por su parte, en la revisión del plan de Coyhaique, el AGIES de fojas $251^{70}$ omitió calcular los costos de fiscalización, lo que la SMA hizo ver en su momento, ${ }^{71}$ aunque no fue subsanado. Para la revisión del plan de Ventanas, el AGIES de fojas $1925^{72}$ tampoco los estimó, pero igualmente lo hizo ver la SMA, ${ }^{73}$ y tampoco fue subsanado. Algo similar ocurrió con los AGIES para el plan de Andacollo, de fojas $534 ;{ }^{74}$ de Temuco y Padre Las Casas, de fojas. $480 ;{ }^{75}$ de Osorno, de fojas $416^{76} \mathrm{y}$ $1242 ; ;^{77}$ de Chillán, de fojas $166^{78}$ y $388 ;{ }^{79}$ de Valdivia, de fojas $556,{ }^{80}$ $1028^{81}$ y $1166 ;^{82}$ y de Talca y Maule, de fojas $495^{83}$ y $1103 .{ }^{84}$

En todo caso, el real paso de avance para sincerar los costos de fiscalización y sanción es la determinación de la carga de trabajo en horas-funcionario (HF), más que la valoración monetaria. Esta posición fue adoptada por la SMA a partir de 2015, cuando fue sometida al escrutinio de la Contraloría por no haber sancionado la totalidad de los incumplimientos reportados de la NE de residuos industriales líquidos. Entonces le informó que, si bien estaba obligada legalmente a cumplir con los principios de celeridad, responsabilidad, eficacia y eficiencia, su expresión material se traducía en consumir $\cong 28.000 \mathrm{HF}$ anuales, lo que equivalía al 56 por ciento de su capacidad sancionadora. ${ }^{85}$

${ }^{70}$ Véase https://goo.gl/F8mkKD.

71 Of. Ord. n. ${ }^{\circ}$ 1059/2015, obtenido por solicitud de transparencia n. ${ }^{\circ}$ AW003T0001938.

${ }^{72}$ Véase https://goo.gl/eJHZ6k.

73 Of. Ord. n. ${ }^{\circ} 1804 / 2016$, obtenido por solicitud de transparencia n. ${ }^{\circ}$ AW003T0001938.

${ }^{74}$ Véase https://goo.gl/WEaap4.

${ }^{75}$ Véase https://goo.gl/c7mY9q.

${ }^{76}$ Véase https://goo.gl/Q9AjZL.

${ }^{77}$ Véase https://goo.gl/a2g3Vh.

${ }^{78}$ Véase https://goo.gl/akhju6.

${ }^{79}$ Véase https://goo.gl/PosV5x.

${ }^{80}$ Véase https://goo.gl/Uo6Km9.

${ }^{81}$ Véase https://goo.gl/7qpBZs.

${ }^{82}$ Véase https://goo.gl/bKVziE.

${ }^{83}$ Véase https://goo.gl/DiK6ea.

${ }^{84}$ Véase https://goo.gl/8aG3Jn.

${ }^{85}$ Véase https://goo.gl/jF94sL. 


\section{CONCLUSIONES}

Como hemos mostrado, los diversos expedientes administrativos revelan una escasa comunicación entre el MMA y la SMA. Esta compleja relación no es nueva, pues ya la Contraloría les ha advertido que deben actuar coordinadamente "durante los procedimientos de dictación de los instrumentos de gestión ambiental, como en la fase de ejecución de los mismos", como indican los dictámenes n. ${ }^{\circ}$ 6.190/2014 y 28.047/2015.

También hemos demostrado que repetidamente el MMA no ha considerado adecuadamente los costos de cumplimiento en los que deberá incurrir la SMA, ni ha incluido en la mayoría de los expedientes administrativos los oficios al respecto, con el fin posible de adoptar prontamente la regulación propuesta, las que convenientemente reflejan costos muy bajos o incluso nulos y, por tanto, transmiten el mensaje de que no requerirán gasto público adicional para su implementación. De esta manera, el MMA captura rápidamente el crédito político de adoptar más regulación, quedando en la SMA su implementación y fiscalización, y, por lo tanto, sujeta a escrutinio futuro. Este patrón de conducta parece ser consistente con la explicación propuesta por Hood sobre el manejo de la culpa y el crédito.

Esto también denota una falta de coordinación y vinculación entre los objetivos políticos de corto plazo del MMA y los objetivos de largo plazo asociados a la protección ambiental efectiva a los que apunta la SMA. Esta lógica ha permeado el sistema regulatorio ambiental, en el que el MMA "desconsidera" completamente su etapa de implementación y fiscalización, y la SMA recuerda que el cumplimiento no es espontáneo, y que, siendo necesaria su vigilancia, esto cuesta tiempo y dinero. Ello es la base de la tensa relación entre ambos organismos.

Incluso, respecto del instrumento que más ha sido utilizado recientemente por el MMA — los PPDA-, ha ocurrido una transacción al utilizar la estrategia de interpretar regulaciones y procedimientos para esquivar o disminuir la culpa (Hood 2011, 19). Como mostramos, la SMA informó al MMA los inconvenientes presupuestarios de la interpretación exclusivista de sus potestades fiscalizadoras y sancionadoras, pues necesitaría 511 funcionarios más y presupuesto adicional de $\cong 16.350 .000 .000$ de pesos (valor 2015). En cambio, una interpretación distinta, en la que no existe tal exclusividad, implicaría 30 funcionarios más y presupuesto adicional $\cong 940.000 .000$ de pesos anuales (valor 2017). 
Si bien la nueva interpretación conlleva un enorme ahorro financiero, desde la perspectiva del MMA y su necesidad de aprobar regulación, sigue siendo inconveniente transparentar esa cifra en un AGIES. Esto es el resultado del diseño institucional, sometido a estrategias de reclamación de crédito político, sin un sistema externo e independiente de control de calidad. Puesto en términos simples, si se plantea ante el Consejo de Ministros para la Sustentabilidad que la SMA necesita $\cong 940.000 .000$ de pesos anuales (valor 2017) para fiscalizar dicho plan (cuyos beneficios ambientales fueron calculados asumiendo pleno cumplimiento), el no tener los recursos necesarios para implementarlo significaría hacer de su aprobación una visible irresponsabilidad.

Por esto, incluso con este cambio interpretativo, se seguirá generando regulación que será pobremente fiscalizada, que pondrá la presión para que la SMA desarrolle una política sancionatoria basada excesivamente en la disuasión general, en el uso del escarmiento para compensar la baja capacidad de detección y procesamiento. Esto ratifica, y también explica, que, más allá de que exista escasa evidencia acerca de las tasas de cumplimiento regulatorio en Chile, la aproximación de la SMA sigue siendo mayormente punitiva en lugar de preventiva (OECD 2016a, 133).

Por otra parte, también es necesario que se discuta seriamente el aumento considerable de los presupuestos del sector ambiental, así como la redistribución de los mismos internamente, pues casi el 55 por ciento del total está localizado en el MMA. Esto debe nacer como consecuencia del diagnóstico sobre las restricciones de personal de la SMA, pues, a pesar de usar las capacidades de detección de organismos sectoriales, existe una pobre capacidad de procesamiento - responsivo o no- de los incumplidores detectados (OECD 2016b, 110-111).

No obstante, más allá de las restricciones de personal de la SMA, es necesario administrar mejor la capacidad existente, aprovechando que el diseño regulatorio permite su manejo responsivo. Así, se ha eliminado legalmente la respuesta única sancionatoria, permitiéndose la colaboración del administrado para volver al cumplimiento, a través de los programas de cumplimiento, o del olvidado procedimiento especial de certificación de conformidad, con las limitaciones correspondientes (Soto 2016, 216-217). Lo anterior permite desplegar una estrategia de represalia equivalente, estableciendo en lo posible una sinergia entre 
sanción y persuasión, que es la base de un sistema responsivo de fiscalización, auxiliado por el escalamiento de sanciones (Ayres y Braithwaite 1992, 25). Dada la alta eficiencia en detección proveniente de las regulaciones sujetas a la modalidad de seguimiento numérico, como ocurre con las NE de procesos, los incumplimientos son fácilmente detectables y sin mayores complicaciones probatorias, pues es el mismo administrado quien los reporta, por lo que se superará fácilmente cualquier estándar probatorio en sede administrativa y judicial, facilitando la negociación de programas de cumplimiento.

Pero tan importante como lo anterior es que, para terminar con la (in)sinceridad regulatoria, no sólo debe obligarse al MMA a que cumpla rigurosamente sus propios reglamentos procedimentales, sino que además es imperioso garantizar que se establezca un organismo independiente que compruebe la calidad de los AGIES y, en general, de toda evaluación de impacto regulatorio a nivel legislativo y reglamentario. Es recomendable que se conciba como un organismo con una instancia de decisión colegiada, con términos escalonados de nombramiento, sin miembros que se integren desde otros órganos del poder ejecutivo o legislativo -o políticamente dependientes de éstos-, pues ello cuestiona su independencia política (Wegrich 2015,371), y que sus decisiones no sean vinculantes. Además, es recomendable que se adopten las aproximaciones neerlandesa y alemana, por cuanto una dimensión ignorada en la determinación de los costos de cumplimiento en los AGIES y en los otros estudios similares a la evaluación de impacto regulatorio es el consumo de tiempo por la Administración y los regulados. Con esto, sin dudas se promoverá la sinceridad regulatoria.

\section{REFERENCIAS}

Acs, Alex \& Charles Cameron. 2013. "Does White House Regulatory Review Produce a Chilling Effect and 'OIRA Avoidance' in the Agencies?". Presidential Studies Quarterly 43 (3): 443-467.

Ayres, Ian \& John Braithwaite. 1992. Responsive Regulation: Transcending the Deregulation Debate. Nueva York: OUP.

Becker, Gary. 1968. "Crime and Punishment: An Economic Approach”. Journal of Political Economy 76 (2): 169-217.

Bergamini, Kay, Ricardo Irarrázabal, Juan Monckeberg \& Cristián Pérez. 2018. "Fiscalización, sanción y control ambiental en Chile. Diagnóstico y propuestas para la Superintendencia del Medio Ambiente y tribunales 
ambientales". En Propuestas para Chile. Concurso Politicas Públicas 2017, editado por Ignacio Irarrázaval et al. Santiago: CIP PUC Chile.

Bermúdez, Jorge. 2013. "Fundamento y límites de la potestad sancionadora administrativa en materia ambiental". Revista de Derecho (Valparaíso) 40: 421-447.

2014. Fundamentos de derecho ambiental chileno. Valparaíso: EUV.

Boettiger, Camila. 2010. "Nueva institucionalidad ambiental". Actualidad Jurídica 22: 429-454.

Cannoni, Leslie, Felipe Riesco \& Cristóbal Osorio. 2015. "El carácter integrador de la legislación y de los instrumentos de gestión ambiental...". Revista de Derecho Ambiental 5: 115-151.

Chell, Elizabeth. 1987. The Psychology of Behavior in Organizations. Londres: McMillan.

Contraloría General de la República (CGR). 2016. Informe final de auditoría $n{ }^{\circ}$ 208/2016. https://goo.gl/MflvXN.

Cordero, Luis, Valentina Durán, Camila Palacios, Violeta Rabi, Andrea Sanhueza \& Anahí Urquiza. 2017. Derribando mitos: propuestas para mejorar el acceso a la justicia ambiental en Chile. Santiago: Espacio Público.

Crawford, Sue \& Elinor Ostrom. 1995. “A Grammar of Institutions”. American Political Science Review 89 (3): 582-600.

Dipres. 2013. Informe financiero $n .{ }^{\circ} 108-06 / 09 / 2013$. https://goo.gl/E5HjeC.

- 2014. Informe financiero $n{ }^{\circ} 38-01 / 04 / 2014$. https://goo.gl/3KfpXr.

- 2015a. Formulario A1 - SMA - Partida 25 Capítulo 03. https://goo.gl/ qEVTno.

- 2015b. Formulario A1 - MMA - Partida 25 Capitulo 01. https://goo.gl/ HufNV7.

- 2015c. Formulario A1-SEA-Partida 25 Capítulo 02. https://goo.gl/6925i8. 2015d. Informe financiero $n .^{\circ} 33-30 / 03 / 2015$. https://goo.gl/Nvvp73.

Fernández, Pedro. 2013. Manual de derecho ambiental chileno. Santiago: Legal Publishing.

Garvie, Devon \& Andrew Keeler. 1994. "Incomplete Enforcement with Endogenous Regulatory Choice”. Journal of Public Economics 55: 141-162.

Hernández, José. 2017. "El problema con las potestades de fiscalización ambiental: ¿déjà-vu?" Revista de Derecho Ambiental 7: 7-34.

2018. "Criterio de diferenciación de normas de emisión para una adecuada aplicación de la reforma ambiental". Revista de Derecho Ambiental 8: 134161.

Heyes, Anthony. 1998. "Making Things Stick: Enforcement and Compliance". Oxford Review of Economic Policy 14 (4): 50-63.

Hodgson, Geoffrey. 2006. "What Are Institutions?" Journal of Economic Issues 40 (1): 1-25.

Hood, Christopher. 2011. The Blame Game: Spin, Bureaucracy, and Self-Preservation in Government. Princeton: Princeton University Press. 
Huntington, Samuel. 1965. "Political Development and Political Decay". World Politics 17 (3): 386-430.

Katz, Ricardo, Gabriel del Fávero \& Lionel Sierralta. 1995. "Bases conceptuales y marco de referencia para la elaboración de políticas ambientales en América Latina". Estudios Públicos 57: 173-192.

Mallea, María. 2014. "La potestad fiscalizadora y sancionatoria de la Superintendencia del Medio Ambiente en Chile". Revista de Derecho (CDE) 32: 135156.

Marneffe, Win \& Lode Vereeck. 2011. "The Meaning of Regulatory Costs". European Journal of Law and Economics 32 (3): 341-356.

Monckeberg, Juan, José Hernández, Kay Bergamini \& Cristián Pérez. 2017. "A propósito de la propuesta de control de los planes de manejo de áreas protegidas del Estado". Estudios Públicos 145: 7-35.

NKR. 2010. Quality through Transparency: With Bureaucracy Reduction to a Modern Way of Legislation. Berlin: NKR.

- 2012. Guidelines on the Identification and Presentation of Compliance Costs in Legislative Proposals by the Federal Government. Berlín: NKR.

North, Douglass. 1989. "Institutions and Economic Growth: A Historical Introduction". World Development 17: 1319-1332.

_. 1994. "Economic Performance through Time". American Economic Review 84 (3): 359-368.

OECD. 1997. Regulatory Impact Analysis: Best Practices in OECD Countries. París: OECD.

-1999. Regulatory Reform in the Netherlands, Government Capacity to Assure High Quality Regulation. París: OECD.

- 2002. Regulatory Policies in OECD Countries: from Interventionism to Regulatory Governance. París: OECD.

- 2011. Integrating the Environment in Regulatory Impact Assessments. París: OECD.

- 2012. Recommendation of the Council on Regulatory Policy and Governance. París: OECD.

—. 2014. Regulatory Compliance Cost Assessment Guidance. París: OECD.

- 2016a. Regulatory Policy in Chile: Government Capacity to Ensure High Quality Regulation. París: OECD.

- 2016b. Environmental Performance Reviews: Chile 2016. París: OECD.

- 2017. Chile Evaluation Report: Regulatory Impact Assessment. París: OECD.

Pinilla, Francisco \& José Hernández. 2016. "Control represivo del daño ambiental y reparación: aspectos probatorios en sede administrativa y judicial". En $L a$ prueba en la litigación pública, editado por Jaime Arancibia \& Alejandro Romero. Santiago: Librotecnia. 
Plumer, Marie. 2013. "Los tribunales ambientales: se completa la reforma a la institucionalidad ambiental". En Anuario de Derecho Público UDP, editado por Javier Couso. Santiago: UDP.

Posner, Richard. 1999. "An Economic Approach to the Law of Evidence". Stanford Law Review 51 (6): 1477-1546.

Riquelme, Paulina, Paula Medina \& Daniela Bustos. 2011. "Nueva institucionalidad ambiental: criterios de diseño para el desarrollo regulatorio". Actualidad Jurídica 23: 229-258.

Superintendencia de Medio Ambiente (SMA). 2017. Cuenta pública. https://goo.gl/ XwCi8o.

Soto, Pablo. 2016. "Sanciones administrativas como medidas de cumplimiento del derecho: un enfoque funcional y responsivo aplicado al régimen sancionatorio ambiental". Ius et Praxis 22 (2): 189-226.

Wegrich, Kai. 2015. "Which Results? Better Regulation and Institutional Politics". European Journal of Risk Regulation 6 (3): 369-371. EP 